\title{
PERSISTENCIA REFERENCIAL, ACCESIBILIDAD Y TÓPICO. LA SEMÁNTICA DE LA CONSTRUCCIÓN ARTÍCULO + POSESIVO + SUSTANTIVO EN EL ESPAÑOL MEDIEVAL ${ }^{1}$
}

CONCEPCIÓN COMPANY COMPANY

Universidad Nacional Autónoma de México

\section{Planteamiento teórico y objetivo}

La referencialidad nominal constituye un ámbito semántico fundamental de las lenguas naturales ya que nos informa del conocimiento que los hablantes tenemos sobre las entidades, lingüísticas y extralingüísticas, que nos rodean, y, en consecuencia, todas las gramáticas tienen expresiones y estrategias sintácticas diversas para la identificación del referente de una entidad y para orientar al oyente, o lector, en la adecuada comprensión de tales referentes. En otras palabras, todas las lenguas poseen formas y construcciones que guían al oyente-lector en la recuperación de información linguiística y extralingüística. Desde los nombres propios hasta las anáforas cero, pasando por una amplia gama de construcciones y formas pronominales y deícticas, todas las lenguas pueden codificar el grado de conocimiento compartido por hablante y oyente o escritor y lector respecto de una determinada entidad. La Gramática Sistémica Funcional de Halliday y Hasan, la teoría de la Información de Prince, la teoría de la Relevancia de Sperber y Wilson, la de la Accesibilidad de Ariel o la de la Topicalidad y Coherencia Textual de Givón son sólo algunos de los marcos teóricos desde los que se ha abordado el estudio de las expresiones referenciales nominales y su mantenimiento informativo en el discurso ${ }^{2}$.

${ }^{1}$ Una versión preliminar y abreviada de este trabajo fue leída en el VI Congreso de Jóvenes Investigadores de Lexicografía e Historia de la Lengua Española (AJIHLE), celebrado en la Universidad de Granada, del 29 al 31 de marzo de 2006.

${ }^{2}$ Cf. Mark A.K. Halliday y Ruqaiya Hasan, Cohesion in English, London, Longman, 1976; Ellen F. Prince, «Toward a taxonomy of given-new information», en Radical pragmatics, P. Cole (ed.), New York, Academic Press, 1981, págs. 223-255; Dan Sperber y Deirdre Wilson, 
Se sostiene en esos marcos que, por lo general, las formas o construcciones referenciales de una lengua pueden tener diversos valores y no están gramaticalmente especializadas o no son exclusivas para significar un determinado tipo o un determinado grado de información referencial; así, un nombre propio no tiene como función única identificar o recuperar información derivada del conocimiento enciclopédico, aunque puede hacerlo, un demostrativo no está especializado para designar objetos sobresalientes y próximos al hablante-oyente, aunque tiene también esa función, o un pronombre personal no está únicamente especializado para recuperar información derivada del contexto lingüístico previo, aunque puede hacerlo. Es decir, las expresiones referenciales conllevan por lo regular diversas funciones gramaticales y pragmático-comunicativas bajo un mismo exponente formal $\mathrm{y}$, en perspectiva tipológica, acorde con los marcos teóricos arriba mencionados, es bastante inusual, según señala Ariel $^{3}$, que las lenguas tengan expresiones referenciales especializadas o exclusivas para aportar solamente un tipo específico de información referencial. Una de estas expresiones referenciales inusuales, por su especialización referencial y por su significado discursivo único, es precisamente el objeto de estudio de este trabajo.

El objetivo específico es analizar la semántica-pragmática y la estructura formal de los sintagmas medievales introducidos por artículo + posesivo del tipo la su alma, el mi sacrificio, los vuestros consejeros. La hipótesis que sustenta este trabajo es que constituyen una construcción muy marcada y especializada para significar tres aspectos informativos estrechamente relacionados: la accesibilidad total del poseedor a través de un poseído introducido por artículo + posesivo que se constituye como un caracterizador, casi a manera de epíteto, del poseedor; el vínculo de complementariedad referencial o integridad semántica entre poseedor y poseído, y la persistencia referencial del poseedor y del poseído mediante el mantenimiento informativo de ambas entidades a lo largo del fragmento narrativo en que aparece el sintagma nominal con doble clítico.

El hecho de que esta construcción tenga un significado referencial exclusivo y tan especializado va de la mano — se puede decir que es icónico- con la manifestación formal muy marcada de la estructura, ya que está introducida

Relevance, Oxford, Blackwell, 1986; Mira Ariel, Accessing noun-phrase antecedents, LondonNew York, Routledge, 1990, y los tres trabajos, entre otros, de Talmy Givón, «Topic continuity in discourse: An introduction», en Topic continuity in discourse. A quantitative cross language study, T. Givón (ed.), Amsterdam, John Benjamins, 1983, págs. 1-43; «Topic continuity in discourse: The functional domain of switch reference», en Switch reference and universal grammar, J. Haiman y P. Munro (eds.), Amsterdam, John Benjamins, 1983, págs. 51-82; «Coherence in text vs. coherence in mind», en Coherence in spontaneous text, M.A. Gernsbacher y T. Givón (eds.), Amsterdam-Philadelphia, John Benjamins, 1995, págs. 59-115.

${ }^{3}$ Cf. Mira Ariel, «Accessibility theory: An overview», en Text representation. Linguistic and psycholinguistic aspects, T. Sanders, J. Schilperoord y W. Spooren (eds.), Amsterdam, John Benjamins, 2002, págs. 29-87, especialmente pág. 30. 
por un doble especificador; esto es, especialización o marcación semántica y marcación formal van de la mano ${ }^{4}$. Es importante señalar que en perspectiva tipológica son muy poco frecuentes los sintagmas con múltiple determinación o sobreespecificados, y menos comunes aún en las lenguas europeas ${ }^{5}$. Por lo tanto, de una expresión referencial tipológicamente poco frecuente y formalmente muy marcada en cuanto que lleva un doble especificador, cabe esperar también un significado pragmático-discursivo especializado. En efecto, una característica ampliamente extendida de las lenguas es que la marcación formal suele ir de la mano de marcación o especialización semántica ${ }^{6}$.

El estudio de las frases del tipo el mi amigo, la su casa, más allá de su propio interés descriptivo para un mejor conocimiento del español medieval, es importante porque atiende a la pregunta fundamental de la variación lingüística y el cambio lingüístico, formulada explícitamente hace casi tres décadas por Bolinger, a saber: «¿en determinado contexto qué razón tendría un hablante para emplear una forma que es más ligera en contenido semántico que otra que es más plena, o viceversa?» ${ }^{7}$. Esto es, ¿qué motiva la elección de una forma lingüística vs. otra, ambas equivalentes desde un punto de vista semántico? En el caso de la construcción artículo + posesivo, la pregunta es la siguiente: ¿por qué mantener una estructura posesiva sobreespecificada en la gramática de una lengua, si otras construcciones posesivas pueden codificar una relación posesi-

${ }^{4}$ La escasa frecuencia de empleo de los sintagmas con artículo + posesivo, comparados con otras estructuras posesivas de la lengua española, apoyaría el carácter marcado y especializado que tienen, ya que es bien conocida la relación entre la mayor frecuencia de empleo de una forma o construcción y su estatus no marcado en la lengua; así, por ejemplo, en el Cantar de mio Cid sólo se documentan 58 sintagmas con doble especificador, frente a casi 450 introducidos por posesivo simple y más de 1000 con artículo y una frase prepositiva adnominal; cf. Concepción Company, «Determinantes al servicio del héroe. Artículo + posesivo en el Cantar de mio Cid», La Corónica. A Journal of Medieval Spanish Language, Culture and Literature, 33:2, 2005, págs. 29-50. Es lógico que las estructuras más frecuentes sean no marcadas y tengan una distribución más flexible así como un ámbito de empleo mayor.

${ }^{5}$ Para la tipología general de la doble especificación, cf. Frans Plank, «Double articulation», en Noun phrase structure in the languages of Europe, F. Plank (ed.), Berlin-New York, Mouton de Gruyter, 2003, págs. 337-395, especialmente pág. 379, y para las lenguas indoeuropeas, véase María Koptjevskaja-Tamm, «Possessive noun phrases in the languages of Europe», en Noun phrase structure in the languages of Europe, F. Plank (ed.), Berlin-New York, Mouton de Gruyter, 2003, págs. 621-722. Las lenguas romances constituyen, por tanto, un islote tipológico en cuanto a esta área de la gramática.

${ }^{6}$ Para el paralelismo entre marcación formal y marcación semántica, cf., entre otros muchos, John Haiman, Natural syntax. Iconicity and erosion, Cambridge, Cambridge University Press, 1985, particularmente el capítulo 3.

7 Dwight Bolinger, «Pronouns in discourse», en Syntax and semantics, volumen 12: Discourse and syntax, T. Givón (ed.), New York, Academic Press, 1979, págs. 289-309. La cita literal de Bolinger es: «At X location, what reason might the speaker have for using a word that is leaner in semantic content rather than one that is fuller, or vice versa?», y corresponde a la pág. 290. 
va referencialmente similar? En otras palabras, si otras construcciones posesivas del español pueden codificar una relación posesiva semejante en la referencia - por ejemplo, entre otras estrategias, mediante posesivo simple, su carta, mediante posesivo duplicado, su carta del rey, o mediante un artículo y una frase prepositiva adnominal, la carta del rey-, dado que todas tienen el mismo referente poseedor y parecen, al menos a primera vista, informativamente similares, ¿qué ventajas comunicativas tenía mantener en el español medieval un sintagma introducido por artículo y posesivo de manera simultánea? Intentaré contestar esta pregunta a lo largo de este trabajo. El punto de partida para analizar la variación lingüística es que, cuando hay varias alternativas gramaticales, la elección nunca es arbitraria o al azar.

El corpus en que se basa la investigación son diez textos medievales, de diversos géneros textuales, correspondientes al siglo XIII ${ }^{8}$, ya que es éste el momento de mayor documentación en los textos de los sintagmas con artículo + posesivo en el español antiguo ${ }^{9}$. Para los fines operativos del análisis, he incluido el Cantar de mio Cid como parte del corpus, a sabiendas del problema de datación de la obra, por ser el primer texto escrito íntegramente en castellano. He analizado una muestra base de 30.000 palabras por texto, seleccionadas por muestreo al azar, ya que es esta la cantidad de palabras aproximada contenida en el Cantar de mio Cid. Cuando el texto no llega a ese universo de palabras, como es el caso de los documentos notariales del periodo o del Fuero de Alcalá, he analizado el texto en su totalidad. El corpus base del análisis está constituido por 898 sintagmas con artículo + posesivo, de los cuales 611 corresponden a posesivos de $3^{\mathrm{a}}$ persona $(68 \%)$ y el resto a $1^{\mathrm{a}}$ y $2^{\mathrm{a}}$. Con fines de

${ }^{8}$ El corpus es el siguiente: Anónimo, Calila e Dimna, edición crítica de Juan Manuel Cacho Blecua y María Jesús Lacarra, Madrid, Castalia, 1984; Anónimo, Castigos del rey don Sancho $I V$, edición crítica de Hugo Oscar Bizzarri, Frankfurt-Madrid, Vervuert-Iberoamericana, 2001; Anónimo, Cantar de mio Cid. Texto, gramática y vocabulario, edición paleográfica de Ramón Menéndez Pidal, volumen 3, Madrid, Espasa Calpe, 1944-1945; Alfonso X, Libro de las cruces, edición crítica de Lloyd A. Kasten y Lawrence B. Kiddle, Madrid-Madison, Consejo Superior de Investigaciones Científicas, 1961; Alfonso X, General estoria. Primera parte, edición crítica de Pedro Sánchez-Prieto Borja, Madrid, Fundación José Antonio de Castro, 2001; Alfonso X, General estoria. Segunda parte, edición crítica de Antonio G. Solalinde, Lloyd A. Kasten y Victor R.B. Oelschläger, Madrid, Consejo Superior de Investigaciones Científicas, 1957; Alfonso X, Setenario, edición crítica de Kenneth H. Vanderford, Buenos Aires, Instituto de Filología de la Universidad de Buenos Aires, 1945; Ramón Menéndez Pidal, Documentos lingüísticos de España. Reino de Castilla, Madrid, Consejo Superior de Investigaciones Científicas, [1919]1966; Anónimo, Fuero de Alcalá (Fuero viejo), edición crítica de María Jesús Torrens Álvarez, Alcalá de Henares, Fundación Colegio del Rey, 2002; Pedro Sánchez-Prieto Borja, Textos para la historia del español, tomo 1, Alcalá de Henares, Publicaciones de la Universidad de Alcalá de Henares, 1991.

${ }^{9}$ Cf. mi trabajo «Artículo + posesivo + sustantivo y estructuras afines», en Sintaxis histórica de la lengua española. Segunda parte: La frase nominal, C. Company (dir.), México, Fondo de Cultura Económica y Universidad Nacional Autónoma de México, en prensa. 
contraste y sólo para algunas variables, he realizado un pequeño fichado adicional de 200 ocurrencias de posesivo simple.

El trabajo está estructurado en cinco apartados además de la presente introducción. En $\S 2$ reviso brevemente los estudios existentes sobre artículo + posesivo en el español, con especial atención a aquellos que han abordado la estructura desde un punto de vista semántico-pragmático. El apartado § 3 está dedicado a definir los conceptos teóricos que conducen el análisis: accesibilidad, persistencia referencial, integridad semántica y gramaticalización en su relación con la construcción objeto de estudio. El apartado § 4, el más extenso, constituye el núcleo del análisis y está dedicado a la semántica referencial y pragmática de la construcción, con atención a las propiedades discursivas de accesibilidad, persistencia referencial e integridad semántica o complementariedad referencial. En $\S 5$ expongo las características formales de estos sintagmas, contrastándolos con las expresiones posesivas introducidas por posesivo simple o por artículo simple, para mostrar que la forma de estos sintagmas está al servicio de su significado, o de otra manera, el significado y el significante de la construcción son solidarios. El apartado $§ 6$ es tanto un resumen de las características de los sintagmas con doble determinación, cuanto unas conclusiones de naturaleza teórica sobre la relación entre forma, significado y texto en el diseño de esta zona de la gramática.

\section{ANTECEDENTES}

Las frases nominales con artículo + posesivo son sin duda un rasgo caracterizador de la sintaxis nominal medieval, que lo opone al español general actual, carente de estas formas ${ }^{10}$. No obstante ello, puede decirse que han merecido poca atención en la bibliografía sobre la diacronía del español, ya que no llegan a una decena los artículos especializados. Los estudios sobre el tema que abordan la semántica de estos sintagmas coinciden en apuntar el carácter huidizo de la construcción, reacia a generalizaciones sintácticas y semánticas, cuya definición debe buscarse más en el nivel estilístico de la lengua que en el gramatical propiamente, ya que parece escapar a reglas, debido a las «grandes diferencias que se presentan no sólo entre autores de un mismo periodo, sino dentro de un mismo autor, o incluso entre pasajes de una misma obra», como señala el estudio, ya clásico, de Lapesa ${ }^{11}$, o como afirma Meier «ha grandes

${ }^{10}$ Quedan residualmente y casi como frases hechas, la mi madre, la mi casa, en el norte de España, zona asturiana, y el occidente: León, Extremadura y Huelva; cf. Company, «Artículo + posesivo + sustantivo y estructuras afines», citado en la nota anterior, y las referencias dialectales ahí citadas.

11 Rafael Lapesa, «Sobre el artículo ante posesivo en castellano antiguo», en Estudios de morfosintaxis histórica del español, R. Cano y M.T. Echenique (eds.), Madrid, Gredos, [1971] 2000, págs. 413-435, pág. 422. 
divergencias de gosto pessoal dos autores» ${ }^{12}$. Todos los trabajos en esta línea caracterizan la construcción como una expresión muy marcada, que aporta valor afectivo, énfasis y realce expresivo o retórico ${ }^{13} \mathrm{o}$ como expresiones enmarcadoras o realzadoras, elementos de focalización que centran la atención del lector $\mathrm{u}$ oyente sobre un personaje o una idea ${ }^{14}$. Ya a fines del siglo XIX, Gessner ${ }^{15}$ señalaba el significado afectivo y familiar de la construcción, y posteriormente el estudio ya mencionado de Lapesa constituyó un trabajo seminal para la configuración de estos sintagmas en términos estilísticos más que gramaticales, análisis secundado por prácticamente todos los historiadores de la lengua que se han ocupado de la construcción. Por lo general, no se hace explícito en esos trabajos en qué consiste el énfasis expresivo, retórico o el carácter afectivo.

La caracterización en términos de estructura huidiza, un tanto errática, reacia a generalizaciones se debe en gran medida, a nuestro parecer, a las enormes diferencias cuantitativas de ocurrencia que los autores observan entre obras de un mismo periodo, o a las grandes variaciones de frecuencia de un género textual a otro, e, incluso, varía dentro de la obra de un mismo autor según los pasajes y temas, y varía también de un autor a otro de una misma época y origen dialectal. Por ejemplo, para el siglo XV, Eberenz ${ }^{16}$ hace notar que la obra de Alfonso de Cartagena tiene un $2 \%$ de artículo + posesivo mientras que los Soliloquios de Fernández de Pecha arrojan un $85 \%$. Para Lapesa ${ }^{17}$, la estructura con doble determinante suele escasear en pasajes literarios «impersonalmente narrativos, pero aumenta en frecuencia y hasta predomina a veces en los fragmentos de carácter poético, retórico o donde hay proximidad

${ }^{12}$ Harri Meier, «'Meu pai - o meu pai'. O artigo antes de adj. possessivo + nome de parentesco na linguagem falada», Boletim de Filologia, 9:2, 1948, págs. 175-190, pág. 179.

${ }^{13}$ Cf. Lore Terracini L'uso dell'articolo davanti al possessivo nel Libro de buen amor, Torino, Facoltá de Lettere, 1951, especialmente págs. 26-28; Alfredo Carballo Picazo, reseña de Lore Terracini, L'uso dell'articolo devanti al possesivo nel Libro de buen amor, Revista de Filología Española, 38, 1954, págs. 303-308; Lapesa «Sobre el artículo ante posesivo», ya citado en la nota 11; Rafael Cano Aguilar, El español a través de los tiempos, Madrid, Arco Libros, 1988, pág. 142; Gloria Clavería Nadal, «La construcción artículo + posesivo en los siglos XIV y XV», en Actas del II Congreso Internacional de Historia de la Lengua Española, M. Ariza, J. M. Mendoza, R. Cano y A. Narbona (eds.), Madrid, Arco Libros, 1992, págs. 347-357, y Rolf Eberenz, El español en el otoño de la Edad Media. Sobre el artículo y los pronombres, Madrid, Gredos, 2000, capítulo 11.

${ }^{14}$ Cf. Josefina Albert Calera, «El uso del posesivo en Berceo», en Actas del IV Congreso Internacional de Historia de la Lengua Española, C. García Turza, F. González Bachiller y J. Mangado Martínez (eds.), Logroño, Universidad de la Rioja, 1998, págs. 321-329, particularmente pág. 328.

${ }^{15}$ Emil Gessner, «Das spanische Possessive- und Demonstrativpronomen», Zeitschrift für Romanische Philologie, 17, 1893, págs. 329-354, especialmente pág. 333.

${ }^{16}$ En su libro, anteriormente citado, El español en el otoño de la Edad Media, págs. 270-271.

${ }^{17}$ En su artículo ya citado «Sobre el artículo ante posesivo», pág. 422. 
afectiva del narrador». Por su parte, Pato ${ }^{18}$ registra muchos más artículo + posesivo en la obra en prosa de Santillana que en la de verso (43\% vs. $20 \%$, respectivamente), cuando, siguiendo el planteamiento de Lapesa, hubiera sido esperable una mayor frecuencia en la obra poética, mientras que el uso del posesivo simple es mucho mayor en la poesía del Marqués que en su prosa. En cambio, Company ${ }^{19}$, en el mismo periodo analizado por Pato, siglo XV, documenta muchas más ocurrencias en textos poéticos que en prosísticos (226 vs. 31 , respectivamente, en un universo cuantitativo de palabras similar en ambos géneros). Clavería ${ }^{20}$ registra un ligero aumento de la construcción en el siglo $\mathrm{XV}$ con respecto al XIV en textos legales $(18 \%>22 \%)$ y señala también que los Soliloquios de Fernández de Pecha son un tanto anómalos en el conjunto de autores de la primera mitad del XV por la elevada frecuencia de la construcción en esa obra ${ }^{21}$.

Algunos trabajos recientes han analizado la relación entre el valor semántico y pragmático de la construcción, las inconsistencias en las frecuencias de uso y un posible proceso de gramaticalización truncado, y muestran que el valor estilístico de la estructura y su recurrente aparición en lugares textuales especiales o dramáticos es consecuencia del significado de la construcción y de las fuertes restricciones formales y distribucionales que mantuvo el sintagma a lo largo de todo el español medieval, de ahí su baja frecuencia general frente a otras expresiones posesivas ${ }^{22}$.

${ }^{18}$ Enrique Pato, «Sobre el artículo con posesivo en español medieval», manuscrito. Agradezco al autor el haberme proporcionado su texto.

19 «Gramaticalización, debilitamiento semántico y reanálisis. El posesivo como artículo en la evolución sintáctica del español», Revista de Filología Española, 81:1-2, 2001, págs. 49-87, especialmente las págs. 84-85.

${ }^{20}$ En su artículo, antes citado, «La construcción artículo + posesivo en los siglos XIV y XV», en particular las págs. 353 y 357.

${ }^{21}$ Ciertamente, los sintagmas con artículo + posesivo muestran una variabilidad cuantitativa casi sorprendente entre textos de una misma época y aun de un mismo género textual. Por ejemplo, para el siglo XIII, periodo base del análisis, los Castigos del rey don Sancho arrojan 326 ocurrencias en 30.000 palabras, el Calila e Dimna 47 ocurrencias en el mismo universo de palabras — que es algo menos de la mitad del universo total de palabras de esta obra—, el Cid 58 documentaciones en poco menos de 30000 palabras y la General estoria. Primera parte, 141 en poco más de 30000; el Fuero de Alcalá sólo tiene 3 ocurrencias en unas 16000 palabras, mientras que los documentos notariales editados por Menéndez Pidal, DLE, y por Sánchez Prieto, THE, para este periodo, unas 15000 palabras entre ambos grupos, arrojan 23 documentaciones. Tales diferencias podrían deberse al género textual - aunque Castigos y Calila se podrían englobar ambos en el género sapiencial y es de suponerse que el lenguaje foral y legal era muy similaro bien al hecho de que, como intentaré mostrar más adelante, es una construcción fórica, casi siempre anafórica, pragmáticamente controlada y no tanto sintácticamente, esto es, guiada o estructurada más por la pragmática del texto que por la sintaxis, aunque ambos niveles de lengua no son fácilmente separables. Ambos factores, estructura pragmática informativa y género textual, pueden estar, desde luego, cooperando en tan diferentes frecuencias de uso.

${ }^{22}$ Cf. Company, «Gramaticalización y frecuencia de uso. Los paradójicos sintagmas con artículo + posesivo en el español medieval», Revista de Historia de la Lengua Española, en prensa. 
En este estudio intentaré mostrar que el análisis tradicional en términos estilísticos es acertado pero debe ser invertido el planteamiento: no es su carácter estilístico el que provoca un comportamiento gramatical general huidizo o errático, sino que es su significado tan especializado para accesibilidad, persistencia referencial e integridad semántica el que motiva un comportamiento gramatical peculiar, incluso un tanto anómalo como sintagma nominal posesivo, y las hace formas ideales para explotación estilística o pragmática, que es siempre altamente dependiente del contexto. En última instancia, el estilo no es sino una explotación, consciente o inconsciente, de los recursos gramaticales disponibles en una lengua. Intentaré presentar las razones del porqué de ese carácter «poco gramatical» y veremos que la estructura sigue pautas regulares, aunque es una construcción muy marcada respecto de otras expresiones posesivas.

\section{ACCESIBILIDAD, PERSISTENCIA, GRAMATICALIZACIÓN Y EL SIGNIFICADO DE} LA CONSTRUCCIÓN

Se hace necesario definir brevemente los conceptos teóricos que guían el análisis: accesibilidad, persistencia referencial, gramaticalización e integridad semántica.

Accesibilidad es el grado en que una entidad es conocida e identificable para el oyente o lector, bien porque haya sido mencionada previamente o bien porque forme parte del conocimiento de mundo compartido entre el hablantenarrador-escritor y el oyente-lector ${ }^{23}$. Se trata de una propiedad gradual de las entidades nominales, ya que la distancia sintagmática y cohesión entre la anáfora y el referente o la distancia entre dos menciones de un referente, su prominencia, ya sea cultural-global ya local-narrativa, la competencia o conflicto de referentes posibles en un mismo tramo discursivo, el cambio de escenario o marco narrativo-temático son factores que pueden afectar la mayor o menor accesibilidad de la entidad o forma en cuestión. En general, se establece una relación inversamente proporcional entre el peso fonológico o complejidad estructural interna de un sintagma y el grado de accesibilidad: a mayor peso fonológico de la forma, menor es el grado de conocimiento del referente de esa forma por parte del oyente o lector, o en otras palabras, a mayor información léxica, menor la accesibilidad del referente, ya que un mayor número de constituyentes en un sintagma es indicativo de que el oyente-lector tiene un menor conocimiento de la entidad referida con ese nominal. Así, por ejemplo, la referencia aportada por un sustantivo es rica informativamente pero supone, por

${ }^{23} \mathrm{Cf}$. los trabajos de Ariel ya mencionados, Accessing noun-phrase antecedents, capítulo 1, y «Accessibility theory: An overview». 
ello mismo, baja accesibilidad en la mente del lector u oyente, esto es, una forma léxica plena implica, por lo regular, que la entidad en cuestión no ha sido presentada previamente, en cambio un pronombre clítico o una anáfora cero son pobres fonológicamente, pero altamente accesibles las entidades referidas a través de estas formas pronominales y marcas morfológicas de concordancia, ya que está implícito que no se expresan léxicamente porque ya han sido presentadas y son, en consecuencia, conocidas del oyente-lector. Este comportamiento general esperado puede ser transgredido por la presencia de determinadas formas gramaticales o por manipulación sintáctica, ya que, como dijimos, la accesibilidad es un concepto gradual y un hecho dinámico que se construye discursivamente $^{24}$. El concepto de accesibilidad se recubre en buena medida con el de información dada, pero he preferido el primero porque, a mi modo de ver, remite a un matiz dinámico y relacional que es idóneo para caracterizar las expresiones posesivas medievales introducidas por artículo + posesivo.

Persistencia es el grado de continuidad referencial con que una determinada entidad se mantiene en el discurso y es un concepto estrechamente relacionado con el de topicalidad ${ }^{25}$. Es, al igual que el de accesibilidad, un concepto gradual y dinámico ya que a mayor prominencia, importancia o carácter topical de una entidad - ya sea porque es importante en el conocimiento de mundo compartido por hablante y oyente, tópico global o extrínseco, ya sea prominente en un texto específico, tópico local o intrínseco-, más posibilidades habrá de que el hablante-escritor siga hablando de esa entidad y de que, en consecuencia, ésta se mantenga y persista en el discurso. Las estrategias de persistencia referencial son diversas, desde léxicas hasta marcas morfológicas, pasando por las estructuras más usuales como son pronombres y formas anafóricas de diverso tipo. El concepto de persistencia es equivalente al ya clásico de 'continuidad topical' empleado por Givón, pero he preferido el menos marcado de persistencia porque en las construcciones introducidas por artículo + posesivo, como veremos, no sólo persiste el poseedor, que es lo esperado por tratarse de la entidad prominente o topical de la relación posesiva ${ }^{26}$, sino que también persiste el poseído, que es, por lo regular, la información nueva de la expresión posesiva.

Una gramaticalización, en su definición tradicional, es un proceso de cambio mediante el cual una forma o construcción, en contextos sintácticos y semánticos específicos, asume una función gramatical, o bien una entidad o cons-

${ }^{24}$ En su libro ya citado, Accessing noun-phrase antecedents, págs. 39-41.

${ }^{25}$ Cf. los dos artículos de Givón intitulados ambos «Topic continuity in discourse», citados en la nota 2, y el libro de María Ángeles Gómez González, The theme-topic interface. Evidence from English, Amsterdam-Philadelphia, John Benjamins, 2001, especialmente el capítulo 5.

${ }^{26}$ Cf. C. Company, «Semántica y sintaxis de los posesivos duplicados en el español de los siglos XV y XVI», Romance Philology, 48:3, 1994, págs. 111-135, y las referencias ahí citadas. 
trucción ya gramatical adquiere una función aún más gramatical ${ }^{27}$. En términos mucho más generales, una gramaticalización puede ser definida como un proceso dinámico constante, nunca concluido, de codificación y organización de gramática, entendida ésta como la cristalización del us ${ }^{28}$.

Una definición complementaria de la anterior es que la gramaticalización consiste en la fijación de estrategias discursivas, de manera que los fenómenos lingüísticos que, en un estado de lengua dado, operan en un nivel discursivo o textual, en un nivel más pragmático, se convierten con el paso del tiempo en construcciones gramaticales convencionales, carentes ya de condicionamientos pragmáticos ${ }^{29}$. Puede suceder, si bien no es muy común en la diacronía de las lenguas, que tales formas nunca se liberen de sus condicionamientos discursivo-pragmáticos originarios y que, por ello, presenten en general un escaso empleo, nunca se generalicen, en consecuencia, no se gramaticalicen plenamente y lleguen incluso a desaparecer. Tal es el caso de los sintagmas nominales introducidos por artículo + posesivo, como he analizado en otro trabajo $^{30}$.

En el caso de artículo + posesivo, la gramaticalización consistió en el cambio de secuencia sintagmática con dos especificadores a construcción: secuencia > construcción, entendida ésta como un acoplamiento indisoluble de forma y significado para un propósito comunicativo específico, y en donde la construcción en su totalidad y no sus integrantes es la que aporta el significado, el cual es idiosincrásico de la estructura en su totalidad; típicamente las construcciones seleccionan entradas léxicas favoritas y tienen un patrón distribucional

${ }^{27}$ Cf., entre muchos otros, los estudios, ya tradicionales, de Jerzy Kuryłowicz, "The evolution of grammatical categories”, Diogenes, 55, 1965, págs. 55-71, en particular la pág. 69; Christian Lehmann, Thoughts on grammaticalization. A programmatic sketch, München, LINCOM Europa, [1982] 1995, y Paul J. Hopper y Elizabeth C. Traugott, Grammaticalization, Cambridge, Cambridge University Press, [1993] 2003, en particular el capítulo 1.

${ }^{28}$ Sigo en esta idea a Paul J. Hopper, «Emergent grammar», Berkeley Linguistics Society, 13, 1987, págs. 139-157, y «Emergent grammar», en The new psychology of language. Cognitive and functional approaches to language structure, M. Tomasello (ed.), New Jersey: LEA, 1998, págs. $155-175$.

${ }^{29}$ Cf., entre otros, Elizabeth C. Traugott «From propositional to textual and expressive meanings: some semantic-pragmatics aspects of grammaticalization», en Perspectives on historical linguistics, W. Lehmann y Y. Malkiel (eds.), Amsterdam, John Benjamins, 1982, págs. 245-271, «Constructions in grammaticalization», en The handbook of historical linguistics, B. Joseph y R. Janda (eds.), Malden-Oxford, Blackwell, 2003, págs. 624-647; José Luis Girón Alconchel, «Procesos de gramaticalización del español clásico al moderno», en Actas del V Congreso Internacional de Historia de la Lengua Española, M. T. Echenique y J. Sánchez Méndez (eds.), Madrid, Gredos, 2002, págs. 103-121, y mi artículo «La gramaticalización en la historia del español», en Gramaticalización y cambio sintáctico en la historia del español, C. Company (ed.), número monográfico de Medievalia, 35, 2003, págs. 1-62.

${ }^{30}$ En «Gramaticalización y frecuencia de uso. Los paradójicos sintagmas con artículo + posesivo en el español medieval», ya citado en la nota 22. 
característico $^{31}$. Las construcciones, como es esperado, surgen del contexto, y la cadena sintagmática artículo + posesivo habría pasado, a través de determinados contextos, de una secuencia libre a una construcción convencional y especializada para un significado específico. El apareamiento de artículo + posesivo es propiamente la construcción, una especie de colocación sintáctica fija o prefabricada, un sentido próximo al de prefab de Bybee ${ }^{32}$, la cual realiza una selección léxica, restringida y determinada por contexto, de las voces capaces de constituirse en núcleo de esa frase nominal. Se trataría de una gramaticalización de construcción, en el sentido de Traugott ${ }^{33}$.

¿Cuál es el significado de la construcción artículo + posesivo? Como ya he anticipado, indica la accesibilidad total del poseedor, la integridad semántica del vínculo poseedor-poseído y la persistencia referencial de ambos. Tal significado viene dado, como es lógico, por el significado de las partes integrantes: los significados deíctico y reflexivo etimológicos originarios del artículo y del posesivo, respectivamente, fueron, en mi opinión, claves para que la construcción adquiriera el significado global que enseguida mostraremos. Se hace necesario, por tanto, caracterizar brevemente la función de cada uno de los dos clíticos introductorios de la construcción.

El artículo, como ya he señalado en otros trabajos, tiene como función única presentar la entidad nominal que sigue como determinada, conocida, accesible al oyente y próxima a la experiencia ${ }^{34}$. Es un deíctico que busca su relación hacia adelante en el sintagma, lo podríamos denominar deixis prospectiva, y una vez que presenta a su nominal no queda ningún residuo informativo pendiente, por lo cual esas frases nominales (FN) son autónomas referencialmente y no relacionales, de manera que una vez introducido el sustantivo, el oyente o lector posee toda la información necesaria para la adecuada comprensión de

${ }^{31} \mathrm{Cf}$. los trabajos de Adele E. Goldberg, A construction grammar approach to argument structure, Chicago-London, The University of Chicago Press, 1995, especialmente el capítulo 1; Constructions at work: The nature of generalization in language, Oxford, Oxford University Press, 2006, y «Generalizing argument structure constructions», comunicación leída en el Linguistic Society of America Annual Meeting, 5-8 de enero de 2006, Albuquerque, New Mexico.

32 Joan L. Bybee, Phonology and language use, Cambridge, Cambridge University Press, 2001, capítulo 1 .

33 «Constructions in grammaticalization», ya referido en la nota 29.

${ }^{34}$ Cf., entre muchos otros, el artículo clásico de Amado Alonso, «Estilística y gramática del artículo en español», en Estudios lingüísticos, volumen 1: Temas españoles, Madrid, Gredos, [1933] 1974, págs. 125-160, en particular la pág. 134; C. Company, «La extensión del artículo en el español medieval», Romance Philology, 44:4, 1991, págs. 402-424, y Richard Epstein, «Reference and definite referring expressions», Pragmatics and Cognition, 6:1-2, 1988, págs. 189-207, especialmente pág. 191; Manuel Leonetti, «El artículo», en Gramática descriptiva de la lengua española, I. Bosque y V. Demonte (dirs.), Madrid, Espasa Calpe-Real Academia Española, 1999, págs. 787-890, particularmente, págs. 795-797; Rosa María Ortiz Ciscomani, «El artículo determinado en el Cantar de mio Cid», comunicación leída en el Congreso Internacional X Jornadas Medievales, Universidad Nacional Autónoma de México, 21-25 de septiembre de 2004. 
esa FN, como se muestra en (1). Es decir, el artículo opera como un presentador y actualizador de un sustantivo, que es conocido y accesible al oyente o al lector.

El conocimiento de la entidad sustantiva puede venir dado por varios mecanismos de actualización, todos ellos se mantienen con plena vigencia hasta el español de hoy; el último, sin embargo, no me ha sido posible documentarlo en el español medieval porque es propio de la lengua oral: a) el nominal ha sido introducido previamente en el texto (1a) (se indica en cursivas la mención previa); $b$ ) el nominal en cuestión no ha sido mencionado, pero se vincula con otro sustantivo que ya ha sido presentado en el texto (1b): conde cabeça, ídolos locura e vanidad, cavallero cavallo; $c$ ) se infiere la existencia del referente aunque el nominal en sí mismo no haya sido mencionado previamente, como en (1c), se trata de un valor próximo a un genérico; $d$ ) es una información conocida de todos en el contexto cultural, de conocimiento y visión de mundo en que se inserta el texto en cuestión: el papa, las tierras de Egipto, como en (1d); e) la entidad tiene un carácter genérico y por ello es conocida de todos $(1 \mathrm{e}) ; f$ introduce FN no anafóricas basadas en la situación, empleo conocido como deixis ad oculos: ¡cuidado con el escalón!, que es dificilísimo, si no es que imposible, de documentar en la lengua escrita, tanto literaria como no literaria.

(1) a. Escrivien cartas, bien las sello, /... / Al rey ondrado le echaron las cartas (Cid, 1958)

-Comamos este camello que anda entre nos... — ¡Confóndate Dios, cómmo eres de mal seso... ¿Non sabes tú que yo he atreguado al camello? (Calila, 160)

b. Aguijaua el conde e penssaua de andar, / Tornando ua la cabeça et catandos atrás (Cid, 1078)

Abraham començól a dezir atrevidamientre, e peró con mesura como ante rey, e dixol todas las razones de los ídolos e de la locura e vanidad (GEI, 1.181)

A todo cavallero que el cavallo se muriere por I año non peche (Fuero de Alcalá, 473.47)

c. Veyen lo los de Alcoçer, Dios commo se alabauan! / «Falido a a myo Çid el pan et la çebada» ( $\mathrm{Cid}, 581)$

d. E por que el papa es cabeça de todos, e todos los otros perlados tienen su lugar por las provincias, e por eso se llama el papa semens pontifex (Castigos, 4.93)

E a muchos annos que non llueve otrossi en las tierras de Egipto (GEII, 1.23.6a)

e. Pues dame agora enxemplo del omne que faze las cosas sin alvedrío (Calila, 263)

La terçera, el baptismo que ffaz enterneçer las cosas duras, ca él amolleçe los pecados (Setenario, 77.7-8) 
El posesivo es una anáfora y, como tal, tiene dos funciones que realizar: introducir a la entidad poseída, tarea similar a la del artículo, pero simultáneamente debe buscar y anclar la referencia del poseedor de esa entidad fuera de su propia FN, por lo regular en la información previamente dada; se trata de una deixis retrospectiva. Cuando se emite una FN encabezada por un posesivo queda una información pendiente: cuál es el poseedor o 'este nominal es poseído de', 'es perteneciente a', información que debe ser completada en el contexto y por tanto los sintagmas posesivos son relacionales y no autónomos referencialmente, como se aprecia en (2a) (se marca en cursivas el poseedor y con subíndices el vínculo anafórico). Cuando se trata de posesivos de $1^{\mathrm{a}}$ o $2^{\mathrm{a}}$ persona el anclaje referencial con el poseedor no está, como es lógico, en el texto, esto es, en el enunciado, sino en el acto de la enunciación. El vínculo fórico, anafórico o catafórico, que se establece con el poseedor impide lecturas genéricas en la entidad poseída de las expresiones posesivas, aun cuando el poseedor sí pueda ser una entidad genérica, como en ( $2 b)$, que refiere a 'todo rey', 'los reyes en general', genericidad que sí es posible en los sintagmas introducidos por artículo simple.

(2) a. Delos yffantes de Carrion $_{\mathrm{i}}$ yo uos quiero contar, / Fablando en su i $_{\mathrm{i}}$ consseio, auiendo $\mathrm{su}_{\mathrm{i}}$ poridad ( $\mathrm{Cid}, 1880$ )

E desque ovo passado todo lo suyo fincó él. ý solo pora fazer su $_{\mathrm{i}}$ oración (GEI, 1.361)

b. Commo quier que el rey $y_{\mathrm{i}}$ sea dado de amar a sus fijos que ha de $\mathbf{s u}_{\mathrm{i}}$ muger de bendiçión (Castigos, 15.165)

Cuando concurren artículo y posesivo en un mismo sintagma, el significado de los dos clíticos contribuye, como es lógico, al significado de la construcción, pero el resultado semántico-pragmático de la construcción total es distinto del de sus partes integrantes; es, como ya dije, un significado de construcción, que es constante, o invariante, y bastante abstracto. Veamos. El artículo nos informa que el nominal que sigue es un referente conocido e importante en esa zona textual; el posesivo, por su parte, nos dice que ese referente pertenece a un poseedor que es topical y protagónico y que ambos, poseedor y poseído, establecen un vínculo esencial entre ellos, el cual es clave en el fragmento discursivo en cuestión, un vínculo que, siguiendo a Tobin ${ }^{35}$, se puede denominar de integridad semántica entre poseedor y poseído. Tal integridad produce, como veremos, un efecto de complementariedad semántica y de equivalencia referencial, ya que, con frecuencia, el poseído repite en buena medida las características o atributos referenciales conocidos o esperables del poseedor, e in-

35 Yishai Tobin, Invariance, markedness and distinctive feature analysis. A contrastive study of sign systems in English and Hebrew, Amsterdam, John Benjamins, 1995, en particular págs. 124-127. 
cluso, también con bastante frecuencia, el poseedor y el poseído tienen la misma base léxica. La razón de ser de los dos clíticos en concurrencia es, por lo tanto, introducir, a través de una sobreespecificación, nominales que constituyen propiedades o vínculos esenciales de un poseedor topical, altamente accesible, y, dada la importancia de poseedor y poseído, la referencia de ambos se va a mantener en el decurso de la narración.

En resumen, la construcción artículo + posesivo es una expresión referencial que se emplea para poner en foco un poseedor, en un determinado pasaje textual, a través de una cualidad o propiedad definidora de él expresada en el sustantivo poseído; es decir, el poseedor es caracterizado mediante el poseído introducido por artículo + posesivo. Opera la construcción como una estrategia gramatical orientadora de la estructuración del texto para informar al lector $\mathrm{u}$ oyente de que el nominal poseído que sigue a un doble especificador constituye una característica inherente y definidora del poseedor y establece con éste una relación de integridad semántica, o de otra manera, el poseedor es tal gracias a tener esa propiedad o cualidad. El poseedor es altamente accesible y topical, por lo común el protagonista de lo que se está narrando, y por ello se va a mantener en el fragmento discursivo en cuestión. Ambos clíticos introducen FN definidas, específicas, cuyos referentes son perfectamente identificables por hablante y oyente dentro de una determinada situación comunicativa y conllevan una información compartida y conocida por ambos, es decir, los dos clíti$\cos$ generan FN con lo que Hawkins denomina anclaje pragmático ${ }^{36}$. En resumen, es una construcción presta a ser empleada cuando el narrador desea poner en foco una entidad a través de ciertas propiedades que le son inherentes y definitorias. Con estos planteamientos en mente, pasemos al análisis detallado de este tipo de construcción en el corpus.

\section{El SIGNIFICADO PRAGMÁTICO-DISCURSIVO DE LA CONSTRUCCIÓN ARTÍCU- LO + POSESIVO}

Analizaremos en esta sección tres variables: 1) la accesibilidad del poseedor, a través del estudio de la distancia entre poseedor y poseído y el conflicto de potenciales poseedores en el fragmento donde se encuentra la construcción artículo + posesivo; 2) la persistencia referencial de poseedor y poseído y la manera, léxica y/o clítico-morfológica, en que mantienen su referencia, y 3) la naturaleza semántica del vínculo entre poseedor y poseído.

${ }^{36}$ John A. Hawkins, Definiteness and indefiniteness: A study in reference and grammaticality prediction, London, Croom Helm, 1978, especialmente capítulo 3. 


\subsection{Accesibilidad y distancia del poseedor}

Un principio operativo en el marco de la teoría de la Accesibilidad es que a mayor proximidad de un elemento fórico con su referente mayor será la accesibilidad de éste para el oyente o lector; es decir, la estructura informativa usual o no marcada en las lenguas es aquella en que existe una relación inversamente proporcional entre accesibilidad y distancia referencial: a mayor distancia $=$ menor accesibilidad del referente ${ }^{37}$. Los posesivos de $1^{\mathrm{a}}$ y $2^{\mathrm{a}}$ persona establecen el anclaje con su poseedor en la enunciación no en el enunciado, por tanto, en el acto de habla, no en la narración, por lo cual en estos casos se puede hablar de anclaje referencial, extratextual o no narrativo o anclaje cero; sólo el posesivo de $3^{\mathrm{a}}$ persona puede ser sometido a un análisis de distancia referencial en el texto.

El uso no marcado de distancia referencial en el caso de expresiones posesivas con posesivo simple es de distancia corta. Ello se debe en buena parte al hecho de que el pronombre-adjetivo posesivo de $3^{\text {a }}$ persona es una forma invariable, $s u(s)$, que sólo indica el número del poseído y es totalmente opaco en cuanto a rasgos referenciales del poseedor, su casa tanto de él-de ella, como de ellos-de ellas y de usted-de ustedes; es, por lo tanto, una forma muy económica, seis referentes bajo un mismo significante, pero es también una forma sumamente opaca. Dada esa total opacidad referencial, el pronombre posesivo establece con su poseedor una referencia, por lo regular, anafórica, en contextos donde éste aparece explícito - ya sea con estructura de frase, ya un clítico, o incluso un morfema verbal de persona indicador de un sujeto expresado con anterioridad- y muy próximo al posesivo, bien en la misma oración donde $s u(s)$ forma sintagma, como en (3a), bien en la oración anterior (3b). Hemos denominado a esta cohesión referencial deixis de distancia mínima ${ }^{38}$. La referencia anafórica del posesivo es reflejo directo del latín y es también la más común en perspectiva tipológica.

(3) a. Todo juvero qui fore in Alcalá $_{\mathrm{i}} \mathrm{o}$ in $\mathbf{s o}_{\mathrm{i}}$ término a quinto tenga los boes (Fuero de Alcalá, 487.144)

b. Honestat e derecho e uerdat dauan los antiguos a Jupiter $r_{\mathrm{i}}$, que auye por $\mathbf{s s u}_{\mathrm{i}}$ natura en ssiete maneras (Setenario, 87.10)

La construcción artículo + posesivo se comporta como una frase posesiva normal en cuanto que su poseedor suele estar previamente nombrado, pero es una

${ }^{37}$ Cf. el libro ya mencionado de Ariel, Accessing noun-phrase antecedents, en particular el capítulo 1 .

${ }^{38}$ Cf. C. Company, «Su casa de Juan. Estructura y evolución de la duplicación posesiva en el español», en Actas del I Congreso Internacional Anglo-Hispano, R. Penny (ed.), Madrid, Castalia, págs. 73-86, en particular págs. 77-78. 
frase posesiva bastante atípica en cuanto que los posesivos de $3^{\mathrm{a}}$ persona establecen con su poseedor una distancia referencial mayor que la que es usual en las FN introducidas por posesivo simple. Muestran frecuentemente lo que se puede denominar deixis débil, en el sentido de que pueden, y suelen, transgredir la regla de deixis de distancia mínima, y por ello en muchos casos es difícil establecer, sin apoyo en un contexto narrativo amplio, quién es el poseedor de la entidad poseída. Se emplea frecuentemente la construcción artículo + posesivo en fragmentos que tienen varios potenciales poseedores, y se pueden caracterizar por ello como pasajes con conflicto de poseedores, si bien el contexto permite asignar la referencia del posesivo. En (4a) se ejemplifican FN con artículo + posesivo que respetan el empleo normal de deixis de distancia mínima, y en (4b) casos que violan esa deixis, puesto que, como se aprecia en los ejemplos, en el mismo contexto próximo hay varios personajes, todos ellos potenciales poseedores del nominal poseído. Sin duda la concurrencia de posibles poseedores en un contexto próximo aminora o debilita, al menos a primera vista, la accesibilidad del poseedor. En los dos ejemplos de (4b) cualquiera de los dos nominales de cada ejemplo, los ebreos o el faraón, Julio César o él, puede constituirse en el poseedor de las sus villas y la su estoria-el su tiempo, respectivamente, pero por contexto se sabe que el fragmento refiere a las villas donde habitaban los hebreos y que es la historia y el tiempo de Julio César, aun cuando faraón y él son nominales más próximos a $s u(s)$ y mejores candidatos a erigirse como poseedor. En (4c) sabemos por conocimiento enciclopédico y del texto que Dios es el poseedor de claridat, aun cuando sintácticamente, e incluso semánticamente, el mejor candidato a poseedor de la FN sobreespecificada es el sol, tanto por estar más próximo al posesivo como porque el sol también irradia claridad; la interpretación de sol como poseedor queda, sin embargo, bloqueada por el hecho de que este nominal aparece como oblicuo tras la FN doblemente especificada. En (4d) es prácticamente imposible, sin ayuda de un contexto muy amplio, saber de cuál de los nominales poseedores es el su fijo o de quién es la su bondat, si de Dios o del santo omne. El poseedor de las construcciones con artículo + posesivo puede estar muy alejado, como en (4e), y por ello es difícil a veces establecer el vínculo estructural, que no contextual, entre poseedor y poseído (los ... indican una o más líneas de texto y los subíndices el anclaje o anclajes referenciales posibles), alejamiento que motiva, aunque muy esporádicamente, como veremos, la mención pospuesta del poseedor en una duplicación posesiva, como en el último ejemplo de (4e).

(4) a. El buen Campeador la $_{\mathrm{i}} \mathbf{s u}_{\mathrm{i}}$ cara tornaua (Cid, 594)

et pero cada uno destos periglos $\mathrm{i}_{\mathrm{i}}$ a su razon de la su $\mathbf{s u}_{\mathrm{i}}$ natura (GEII, $1.105 .18 \mathrm{~b})$

Et dizen que en tres cosas se deve el seglar $r_{\mathrm{i}}$ emendar: en la su $\mathbf{s u}_{\mathrm{i}}$ vida, et afiar la $\mathbf{~ s u}_{\mathbf{i}}$ anima por ella (Calila, 98) 
E por esta una santa iglesia son saluos todos los christianos que derecha mente creen en ella e que resçiben délla $a_{\mathrm{i}}$ todos los sus sacramentos $_{\mathrm{i}}$ (Castigos, 4.93)

b. De cómo los ebreos sirvieron a Faraón $_{\mathrm{j}}$ en alimpiar de suziedades las sus $_{\text {ij }}$ villas $(G E I, 2.13)$

E Julio César ${ }_{\mathrm{i}}$ iva empós él, como lo contaremos todo adelante en la $\mathbf{s u}_{\mathrm{ij}}$ estoria e en el $\mathbf{s u}_{\mathrm{ij}}$ tiempo, que fue en cabo de la quinta edad (GEI, 1.219)

c. La claridat es tan grande de Dios $_{\mathrm{i}}$ que pasa todas las claridades,... e que rresplandeçíe su cara commo el ssol $_{\mathrm{j}}$. Ca los ssus $_{\mathrm{ij}}$ rayos echa ssobre el ssol e ssobre las otras estrellas (Setenario, 85.3)

d. La terçera por que el criado será fijo de algund su amigo que aurá fecho alguna grand cosa en amistad por él $l_{\text {j }}$ por la qual se terná por bien andante aquél $_{\mathrm{i}}$ en criar el su $\mathbf{~ s i j}_{\mathrm{ij}}$ fijo (Castigos, 5.100)

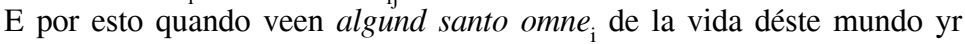
para el otro, cuydan que gelo faze Dios por mal e non por bien, y non es asý. Ca Dios $_{\text { tiral }}$ de la presión e de la maldat déste mundo, e por la su bondat ${ }_{\mathrm{ij}}$ lléualo a la su santa gloria (Castigos, 3.90)

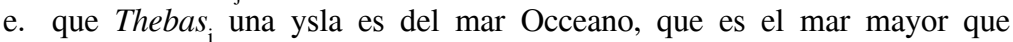
çerca toda la tierra aderredor, et que yaze entre septemtrion... et ua de la

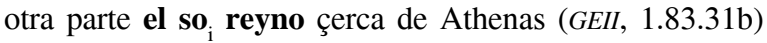

E este rey de que te agora fablo estaua uestido vnos pannos cubiertos de oro e de seda. E por esto se entienden por el oro las riquezas e las noblezas que ha el rey del regno. E por la seda, las aposturas que deue auer en sí, ca las aposturas non las puede amostrar conplida mente nin continuada mente synon ouiere riquezas en las muestre. Los sus pannos déste rey eran orofresados en aljófar e con piedras preçiosas (Castigos, 11.143)

El cuadro 1, a continuación, mide la distancia referencial que tiene la construcción artículo + posesivo con posesivos de $3^{\mathrm{a}}$ persona, y se compara con la distancia referencial que muestran las expresiones con posesivo simple. Aunque la accesibilidad es una propiedad gradual, para efectos operativos del análisis, he establecido dos tipos de distancia: corta, cuando el poseedor se encuentra léxicamente mencionado en la misma oración de la $\mathrm{FN}$ con artículo + posesivo o en la oración inmediatamente anterior, como en los ejemplos de (4a) y (4b) arriba, y larga cuando la última mención léxica del poseedor aparece dos a más oraciones previas al sintagma nominal posesivo, como en (4c) y (4e). Puede verse en el cuadro que la FN con doble especificador prefiere, como expresión posesiva que es, anclajes referenciales de distancia corta (66\%), pero se documenta un número nada desdeñable de casos con distancia larga: $34 \%$, que son muchos, si se los compara con el $16 \%$ de anclaje de distancia larga en las expresiones con posesivo simple. De ahí la caracterización anterior de la construcción artículo + posesivo como expresión posesiva atípica, ya que transgrede la distancia usual de anclaje referencial en el posesivo. Vamos a ver ense- 
guida que hay una motivación semántico-pragmática para esta transgresión de la distancia deíctica posesiva común del español.

\section{CUADRO 1}

Distancia de anclaje referencial del poseedor

\begin{tabular}{llll}
\multicolumn{2}{r}{ Artículo + Posesivo } & \multicolumn{2}{c}{ Posesivo simple } \\
Corta & Larga & Corta & Larga \\
$66 \%(402 / 611)$ & $34 \%(209 / 611)$ & $84 \%(168 / 200)$ & $16 \%(32 / 200)$
\end{tabular}

El hecho de que las construcciones objeto de estudio establezcan con tanta facilidad una deixis de distancia larga genera, como ya señalé, frecuentes pasajes con conflicto de potenciales poseedores: $17 \%$ de los casos de distancia larga muestran competencia de posibles poseedores, y también algunos pocos ejemplos de distancia corta tienen tal conflicto en la asignación estructural del poseedor. En cambio, de la muestra de posesivo simple, sólo $3 \%$ de casos presentó conflicto de poseedores. Vuelve, por tanto, a ser la construcción artículo + posesivo una expresión posesiva muy poco común.

¿A qué se debe la frecuente transgresión del principio de deixis de distancia mínima que realiza la construcción artículo + posesivo y cómo se puede sostener, entonces, la hipótesis de que es una construcción especializada para indicar la alta accesibilidad del poseedor? La respuesta reside en el carácter altamente topical de sus poseedores ${ }^{39}$. Son en su gran mayoría entidades sobresalientes, tópicos primarios, que participan de la línea narrativa principal $^{40} \mathrm{y}$ que con gran frecuencia son los protagonistas de lo que se está narrando, por ello son altamente accesibles puesto que se pueden identificar de manera rápida y clara, sin importar la distancia referencial entre poseedor y poseído. Artículo + posesivo resulta, sin duda, una construcción un tanto paradójica o contradictoria, ya que suele operar con distancias deícticas largas y aun así indica la alta accesibilidad del poseedor.

El poseedor puede ser tanto lo que se denomina tópico global, como se ejemplifica en (5a), aquella entidad que es relevante e identificable con independencia del contexto, esto es, tópicos derivados del conocimiento enciclopé-

${ }^{39}$ La noción de tópico suele ser en la bibliografía consultada bastante polisémica. Para los fines de este análisis entenderemos que un tópico es una entidad, o fragmento, importante, focalizada en el discurso, fácilmente identificable y recuperable, sobre la cual se realiza una predicación, ya sea sobre su totalidad o sobre alguna de sus partes, y es una entidad que suele tener la característica de persistencia o continuidad referencial, es decir, suele seguir siendo nombrada en el discurso subsecuente a su aparición, con diferentes estrategias: clítico, marca de concordancia de la flexión verbal o lexicamente mediante pronombre personal o frase nominal; cf., entre otros, los estudios de Givón citados en la nota 2.

${ }^{40}$ Para la distinción entre los diversos tipos de fragmentos narrativos y sus correlatos sintácticos, cf. Ariel, «Accessibility theory: An overview», ya referido, en particular las págs. 32-34. 
dico y de la situación cultural en que se produce un determinado texto, por ejemplo, el rey, Dios, el sol o personajes históricos y bíblicos, cuanto tópico local, (5b), aquella entidad que es el protagonista de lo que se está narrando, como el Nilo en el pasaje correspondiente al libro V del Génesis en la Primera parte de la General estoria, o las hijas del Cid en el fragmento del ultraje en el Cantar. Ambos tipos de poseedor tópico pueden coincidir en un texto, (5c), como en el caso del Cantar de mio Cid, que tiene como tópico global al héroe, pero también el Cid es el tópico local en muchísimos pasajes del poema, o en el caso de Castigos, que tiene como protagonista, tópico y sujeto constante de comparación a Dios. En los ejemplos de (5) se indican en cursivas las sucesivas menciones del tópico.

(5) a. Dize el rey Salamón que verdat e justiçia mantiene al rey e lo guarda, e buena andança e la clemençia afirman la su silla en que él está asentado. Por la verdat es el rey guardado de los suyos. E por esta verdat regna él sobre ellos e guardan los omnes el su sennorío. La justiçia es $s u$ ofiçio e da themor a aquéllos sobre que él regna por que non le yerren (Castigos, 13.160-161)

b. E pues que del Nilo fiziemos emiente queremos contar las maravillas d'él, como nace e corre, e de las cosas que se en él crían, e de los sos fechos más maravillosos que de todos los otros ríos que en el mundo son (GEI, 1.216)

c. Venido es a moros, exido es de christianos; / En la su vezindad non se treuen ganar tanto. / Agardando seua myo Çid con todos sus vasallos $(\mathrm{Cid}, 567)$

En menor medida, los sintagmas con artículo + posesivo refieren a poseedores que aparecen en la línea narrativa principal pero que no son el tópico primario, no son los protagonistas de la narración, sino que son entidades relevantes en cuanto al vínculo que tienen con el poseedor en esa narración y contribuyen a caracterizar y apoyar la jerarquía del tópico primario, por ejemplo, una reina, cancilleres y embajadores o el rey enemigo para un rey, un siervo para el rey, o bien la iglesia y las autoridades eclesiásticas para Dios, etc., como se ve en (6). En resumen, una propiedad referencial característica de la construcción artículo + posesivo es no vincularse a poseedores que relaten o pertenezcan a aspectos generales de la narración, ya que se documentan siempre en lo que se denomina línea narrativa principal.

La dezena cosa que non prometas nin des cosa por que de ti mismo que eres sennor ouieses a fazer sennorío e fizieses sennor de ti a aquel a quien pusieses el su pie sobre la tu garganta (Castigos, 15.165) que aquello significa demás que las cauallerías et las sus yentes se mouerán escontra el rey (Cruces, 53.45a)

Por lo tanto, dado el carácter altamente topical del poseedor, conocido de todos 
en el texto o en la cosmovisión del mundo medieval, su accesibilidad no se altera y sigue siendo elevada, y por lo mismo, aunque exista conflicto de poseedores, son escasísimos los casos de frases con artículo + posesivo que lleven el poseedor pospuesto como ocurría en el último ejemplo de (4e) arriba, ya que no interesa o no es pertinente o no es necesaria la desambiguación del poseedor, puesto que su carácter de tópico primario constituye una guía informativa suficiente para que el oyente o lector pueda anclar adecuadamente la referencia, además de que el rasgo de integridad o complementariedad semántica que posteriormente analizaremos guía el vínculo poseedor-poseído. No obstante, los frecuentes fragmentos con conflicto de poseedores deben influir - aunque no son la causa fundamental — para que el poseedor se siga mencionando léxicamente y no sólo morfológicamente o mediante clíticos, como, de acuerdo con Ariel ${ }^{41}$, sería lo esperado de una entidad altamente accesible desde el punto de vista informativo.

El posesivo simple, como estructura no marcada frente a la de artículo + posesivo, puede, por supuesto, vincularse a tópicos primarios, pero también a otro tipo de poseedores que no aparezcan en la línea narrativa principal.

\subsection{Persistencia referencial de poseedor y poseído}

La organización informativa no marcada en las lenguas es aquélla en que una vez presentada o introducida una entidad, ésta es retomada mediante mecanismos de bajo peso fonológico, tales como afijos flexivos de concordancia o clíticos, o bien pronombres personales tónicos en ciertas situaciones, mientras que continuar repitiendo léxicamente el nominal en cuestión es una estrategia muy marcada ${ }^{42}$. Pues bien, una de las propiedades referenciales más llamativas de la construcción artículo + posesivo es el mantenimiento léxico de las dos entidades que construyen la expresión posesiva: persiste léxicamente el poseedor y persiste también léxicamente el poseído, produciendo un notable efecto repetitivo léxico en los fragmentos discursivos en que aparecen sintagmas con doble especificador, como se aprecia en los ejemplos de (7) y (8); me atrevo a calificar la construcción como de una machacona persistencia referencial léxica. La mención del poseedor viene desde varias líneas anteriores a la construcción, como es lógico por ser las expresiones posesivas de carácter esencial-

${ }^{41}$ En su libro Accessing noun-phrase antecedents, en particular las págs. 57-58 y 73.

${ }^{42}$ Cf., entre otros, Ariel, Accessing noun-phrase antecedents, págs. 69-71; Chris Barker, «Definite possessives and discourse novelty», Chicago Linguistic Society, 28, 1992, págs. 26-41, en partricular las págs. 29-32; Givón, «Coherence in text vs. coherence in mind», en Coherence in spontaneous text, citado en la nota 2, en especial la pág. 70; y Gómez González, The themetopic interface, ya mencionado en la nota 25 , capítulos 4 y 5 . 
mente anafórico, pero también el poseído puede haber sido introducido previamente a la construcción, mediante artículo u otros presentadores, y es retomado en ésta para luego mantener su referencia. En (7) se ejemplifica el mantenimiento referencial del poseedor y en (8) el del poseído: los poseedores Cilix, Adán y Nuestro Señor se repiten y sostienen referencialmente, los poseídos casa, obispo y clemencia se repiten igualmente. Con frecuencia, persistencia de poseedor y de poseído van a la par. Los ejemplos son algo extensos para que el lector pueda apreciar la insistente continuidad léxica de poseedor y poseído, que excede con frecuencia los límites del párrafo, y que caracteriza en la mayoría de los textos del corpus a la construcción artículo + posesivo. Como es de esperar, además de la repetición léxica, la continuidad referencial puede ir acompañada de mecanismos de bajo peso fonológico, que son más usuales o no marcados para producir continuidad. Se marcan en negritas las menciones léxicas de poseedor y poseído, y en cursivas los mecanismos de persistencia referencial de bajo peso fonológico.

(7) a. et por que andaua y por mayor Phenix que Cilix quisieran algunos llamar el nombre de Phenix a Cilix e aun la su tierra, mas cierta mientre Cilix fue el rey daquel reynado e del nombre del llamaron a essa tierra Cilicia; et dize esse Libro de las Prouincias e otras estorias que fue Cilix... [continúa hablando de Cilix y de la tierra Cilicia] (GEII, 1.83.9)

b. Cuando Nuestro Señor Dios aduxo delante a Adam, como avemos dicho, todas las animalias que él fiziera en la tierra por veer qué las llamarié Adam e qué nombres les dirié, lo uno porque eran todas las animalias pares, maslo e fembra cadaúnas en sus naturas, e non avié ý ninguna pora Adam, lo ál porquel pareció en el contenent de la su cara que se non deleitava él en ninguna de aquellas creaturas,... E él durmiendo tomól una de las costiellas e enchió de carne el logar donde la tomara, e fizo de aquella costiella la mugier. E desí adúxola a Adam e mostrógela. E Adam cuando la vío dixo: — iOh, este huesso era de los mios huessos e carne de la mi carne! (GEI, 1.9-10)

c. Otrosí Nuestro Ssennor Ihesu Cristo ssemeió al pez en auer criança; que assí commo crían ellos cabo la tierra, poniendo ssienpre ssus hueuos, otrossí Nuestro Ssennor Ihesu Cristo ffizo peçes a los ssus ssieruos que crouyeron en él e púsolos cabo la tierra (Setenario, 111.29-30)

(8) a. Et sepas que los signos que dezimos que son enemigos del signo,..., son la su quarta casa, et la su decima, et la su septima, et la su segunda, et la su duodecima, et estas son enemigas... Et las que son de flaqua enemiztat son la su viii ${ }^{a}$ casa et la su sexta [continúa refiriendo las casas y los signos que las controlan] (Cruces, 121.40-45b)

b. E fueron ý todos los nobles de Egipto, e muchos otros de sus fronteras, e vino ý el su obispo, el mayor que los gentiles d'allí avién; e era omne muy anciano e de gran sentido, e muy sabio en todos los saberes. E Julio César temiése de muerte a traición, e guardávase. E el obispo Acoreo seyé allí en un estrado muy noble que le mandara fazer Julio 
César, e pues que cenaron acostárase aquel obispo Acoreo en el estrado, e seyése assí allí, su barva grand e cana e $s u$ mitra en la cabeça como obispo. E Julio César, por detener los omnes que se non adurmiessen y $l$ guardassen cató contra aquel obispo Acoreo, e sabié d'él cómo era ell omne más sabio de Egipto e el más anciano, e por amor de velar començó a entrar en sus palabras buenas con él e moverle razones luengas e altas (GEI, 1.220)

c. E otrosí a menos de ser acatada la pena que el derecho manda sobre aquel yerro non ay logar para obrar el rey de la su clemençia, ca todos los omnes no son sabidores nin foreros de fueros e de leyes... Sy por la clemençia del rey non escapare, son çiertos que la su vida toda está en la clemençia del rey... La quarta cosa que de suso he dicha sobre que el rey deue mucho meter mientes que quando le demandaren en que faga la su clemençia que pare primero bien mientes e sepa bien por raýz la verdat del fecho sy aquel yerro sobre que demanda la su clemençia, si fue cosa que acaesçió por yerro o por ocasión (Castigos, 12.156)

Se observa en los textos medievales analizados que la persistencia referencial puede ser de dos tipos: a) directa, cuando se repite la misma entrada léxica, como en los ejemplos de (7) y (8), sin duda la más frecuente en los textos que integran el corpus, o b) asociativa, donde el nominal poseído o poseedor en cuestión puede o no repetirse él mismo, pero se nombran en ese fragmento otros sustantivos asociados a aquél, con los cuales el poseedor y/o poseído establece una relación de tipo metonímico: estrellas cielos Saturno, Júpiter, Mars (GEI, 1.223); planetas signos acendent (Cruces, 146.53b); grant merçed grant piadat (Calila, 197), santa María madre de nuestro señor Dios (Cid, 2524), produciendo un efecto similar de persistencia referencial, aunque algo menos repetitivo. Las dos estrategias indican la especialización de la construcción artículo + posesivo para mantener en el discurso las dos entidades que integran la expresión posesiva.

La construcción artículo + posesivo puede ser caracterizada, en cuanto a las propiedades de accesibilidad y persistencia, como una estructura posesiva atípica y muy marcada o especializada puesto que tiene lo que considero se puede denominar discrepancia informativa: el poseedor es altamente topical y por lo mismo accesible, según vimos en $\S 4.1$, y a pesar de ello se sigue nombrando léxicamente, y el poseído también se sostiene léxicamente, aun cuando ya ha sido introducido y es perfectamente conocido. Lo no marcado sería en ambos casos emplear mecanismos de bajo peso fonológico sin repetir el mismo lexema base.

Esta elevada especialización depende, según creo, de dos parámetros asociados de distinta naturaleza: $a$ ) de un lado, del hecho de que los poseedores son altamente topicales y accesibles y es lógico que se mantengan discursivamente y de que los poseídos suelen ser temáticos, ya que muchas veces constituyen el tema a desarrollar informativamente: la clemençia del rey, la tierra 
del rey Cilix, el obispo de los egipcios, en los ejemplos anteriores de (7) y (8), y $b$ ) de otro lado, del hecho de que artículo + posesivo forman una construcción, y un rasgo característico de las construcciones en general es que suelen producir efectos de activación (priming) ${ }^{43}$, en el sentido de que una vez que se introducen en el discurso suelen volver a aparecer y tienen un patrón de distribución característico y restringido. Un rasgo sobresaliente de la construcción artículo + posesivo es, en efecto, su capacidad de activar tanto la repetición léxica de poseedor y poseído — vista en muchos de los ejemplos anteriores-, cuanto la capacidad de activar la construcción misma. En efecto, una constante de los textos que integran el corpus es el concentrado narrativo de la construcción: puede haber largos pasajes sin que aparezca un sintagma con artículo + posesivo, pero una vez que aparece uno, otros sintagmas doblemente especificados suelen concurrir a lo largo del fragmento en cuestión, de manera particular si se trata de estilo directo o en pasajes dependientes de verbos de lengua y pensamiento.

Los cuadros 2 y 3 a continuación miden cuantitativamente la persistencia referencial de la construcción, poseedor y poseído, respectivamente, comparándola con sintagmas introducidos por posesivo simple. Se consideran sólo los casos con posesivo de $3^{\mathrm{a}}$ persona, ya que cabe esperar que la persistencia para posesivos de $1^{\mathrm{a}}$ y $2^{\mathrm{a}}$ persona sea aún mayor, dado el carácter inherentemente topical, relevante y altamente accesible de los protagonistas del acto de habla. La persistencia, al igual que la accesibilidad, es una propiedad discursiva de naturaleza gradual; no obstante, para mostrar mejor el contraste entre artículo + posesivo y posesivo simple he operado con presencia-ausencia de la variable 'persistencia léxica'. En la casilla de no persistencia léxica asigné aquellos casos en que el poseedor no se mantiene léxicamente tras la aparición de la construcción - puede persistir mediante anáfora cero, clíticos u otro tipo de pronombres, pero los he considerado como de no persistencia léxica por ser aquéllos los mecanismos no marcados- y en persistencia aquéllos en que sí se mantiene léxicamente el nominal poseedor y/o poseído, con al menos una mención léxica tras el sintagma doblemente especificado.

\section{CUADRO 2}

Persistencia léxica del poseedor

Artículo + Posesivo

Persistencia No persistencia

$63 \%(388 / 611) \quad 37 \%(223 / 611)$
Posesivo simple

Persistencia No persistencia

$21 \%(42 / 200) 79 \%(158 / 200)$

${ }^{43}$ Cf. Adele E. Goldberg, «Generalizing argument structure constructions», ya referido en la nota 31 . 


\section{CUADRO 3 \\ Persistencia léxica del poseído}

\begin{tabular}{llll}
\multicolumn{2}{c}{ Artículo + Posesivo } & \multicolumn{2}{c}{ Posesivo simple } \\
Persistencia & No persistencia & Persistencia & No persistencia \\
$51 \%(311 / 611)$ & $49 \%(300 / 611)$ & $6 \%(13 / 200)$ & $94 \%(187 / 200)$
\end{tabular}

Puede verse en los cuadros anteriores que la construcción artículo + posesivo está más especializada para la persistencia referencial del poseedor que para la del poseído: $63 \%$ vs. $51 \%$, respectivamente, como es de esperar por ser el poseedor el miembro que se considera tópico e información conocida en la relación posesiva, y que en cuanto a la segunda, parece, al menos a primera vista, un tanto indiferente, ya que presenta casi los mismos porcentajes en la casilla de persistencia léxica del poseído que en la de no persistencia. Sin embargo, al comparar cuantitativamente estos resultados internos con los arrojados por posesivo simple, es posible percatarse de que artículo + posesivo es efectivamente una construcción marcada en cuanto a la persistencia de las dos entidades que integran la expresión posesiva: la persistencia del poseedor con artículo + posesivo triplica la del posesivo simple: $63 \%$ vs. $21 \%$, cuadro 2 , y es ocho veces mayor en el caso del poseído: $51 \%$ vs. $6 \%$. Se infiere asimismo de esta última diferencia numérica que la persistencia referencial léxica del poseído es una estrategia muy marcada o especializada, mucho más que la de poseedor ${ }^{44}$.

En los ejemplos de (9) puede apreciarse el uso general del posesivo simple: el poseedor puede o no persistir léxicamente (9a), aunque normalmente no lo hace, no al menos con la repetitiva insistencia léxica con que se mantiene en los casos de artículo + posesivo; se mantiene eso sí, como es lo usual, con estrategias de bajo peso fonológico, como se aprecia en el segundo ejemplo de (9a). El poseído introducido por posesivo simple, (9b), muy raramente persiste, ni léxicamente ni por medios anafóricos, lo normal es que no se mantenga. Además, puede verse en (9) que las estructuras con posesivo simple presentan mucha mayor variedad temática de poseídos, y también de poseedores, y no producen el efecto de activación o priming característico de la construcción

${ }^{44}$ Una interesante relación diacrónica, un tanto paradójica, en la sintaxis histórica de la frase nominal en español es la existente entre los sintagmas posesivos precedidos de artículo determinado, el mi amigo, la su casa, y los precedidos por artículo indeterminado, un mi mensajero, un su amigo. La propiedad de persistencia referencial aquí analizada que tenían los primeros en el español medieval es la que ahora presentan, aunque en menor grado, los segundos en las variedades hispanoamericanas que poseen la estructura, como si al perderse los primeros, las afinidades formales y semánticas de un su amigo con el mi amigo hubieran hecho posible que las de artículo indeterminado adquirieran el significado que tenían las de artículo determinado, llenando así un vacío estructural; cf. Concepción Company, «Frecuencia de uso y contacto lingüístico. La construcción artículo indefinido + posesivo + sustantivo en el español americano», Spanish in Context, 2:2, 2005, págs. 131-156. 
artículo + posesivo. En los ejemplos, se indica en cursivas el poseedor y sus subsecuentes menciones, cuando las hay, y en negritas el sintagma posesivo.

(9) a. Et otrossi quando tu quisieres saber quando saldrá aquel homne preso et encarcerado de su presion et de su carcer, para myentes ad aquella planeta que significo aquella presion (Cruces, 126.51b)

$\mathrm{E}$ si omne alguno él se cayere de su bestia e muriere non responda por ello. E si negare per su ganado e el otro jo firmare con II alcaldes o con III bezinos, preste 1 , e dé el dañador o peche el omezillo (Fuero de Alcalá, 509.284)

b. Non se deve ninguno meter a peligro podiendo estorçer, ca si muere, pierde su alma et peca, et si vençe es ventura. Mas el omne de buen entendimiento pone la lid en fin de todas sus artes, et dizen: - Non despreçies al enemigo flaco et desonrado, et más si fuere artero, quanto más el león que e stan atrevido et tan fuerte (Calila, 163)

$\mathrm{E}$ atan grand afazimiento cayó entre ellos que se ouieron a besar. E quando el hermitanno quiso su voluntad conplir a más, cuydando que teníe muger çerca sí, desfízose entre manos. E el diablo dio salto ençima de una viga... (Castigos, 37.275)

La lectura y análisis de los textos que integran el corpus nos informan que la persistencia referencial léxica del poseedor y del poseído constituye un rasgo idiosincrásico, posiblemente el rasgo idiosincrásico, de la construcción artículo + posesivo. Sin embargo, es necesario señalar que existe una variación cuantitativa muy importante en cuanto a este parámetro en los textos examinados: hay textos con una persistencia léxica muy fuerte de poseedor y de poseído, como serían los casos de Castigos, Cruces, Cid y la General estoria en sus Primera parte y Segunda parte, con tres o más menciones léxicas del poseedor y las mismas o más del poseído, ejemplos de (9) arriba, mientras que otros textos, como el Calila e Dimna, el Fuero de Alcalá y los documentos legales analizados casi no presentan persistencia del poseído y muy ligera en cuanto al poseedor ${ }^{45}$; el Setenario estaría en un punto intermedio entre estos dos grupos textuales, ya que presenta pasajes con fuerte persistencia y pasajes sin ella.

Lo anterior plantea un serio problema, para el que por ahora no tengo una respuesta, y para el que posiblemente no exista respuesta alguna. A saber: ¿la persistencia referencial léxica es un hecho de la gramática de la construcción o es un hecho de ciertas tradiciones discursivas medievales que repiten léxica-

${ }^{45}$ Podría pensarse que el lenguaje foral o legal no propicia la persistencia léxica en la construcción artículo + posesivo porque tiene una estructura con un entramado discursivo mucho más simple que una obra historiográfica o un texto sapiencial. Sin embargo, aunque este hecho estructural puede sin duda estar incidiendo y constituye una posible explicación para los textos legales, el Calila parece constituir una excepción: no tiene la estructuración discursiva ligera de los textos legales pero se aproxima a ellos en la débil persistencia referencial, y se aleja totalmente en la manifestación de esta propiedad de los otros textos examinados que podrían considerarse también sapienciales, Castigos, y en cierta medida el Setenario. 
mente las entidades involucradas en un evento dado? La respuesta no es fácil y pudiera ser, posiblemente es, un problema circular, porque no es posible aislar la gramática de una lengua de las tradiciones discursivas y géneros textuales en que ella se manifiesta y son su soporte textual, aun más problemático para estados pretéritos de lengua. Por una parte, el hecho de que en textos de diverso género textual se encuentren las mismas pautas parece sugerir que la persistencia léxica sí es un rasgo de la construcción —como creo- e igualmente, las diferencias cualitativas y cuantitativas con las expresiones posesivas simples apoyan la idea de que es una propiedad de la construcción, pero, por otra parte, el hecho de que, por ejemplo, el Calila e Dimna arroje diferencias cuantitativas y cualitativas tan fuertes respecto de otros textos morales o sapienciales pone en tela de juicio el planteamiento en términos gramaticales. No en vano la caracterización de Meier y Lapesa ${ }^{46}$ como una estructura más estilística que gramatical.

\subsection{El vínculo poseedor-poseído: integridad semántica}

El significado de la construcción artículo + posesivo, como ya dijimos, es mostrar que el nominal poseído que sigue tras un doble especificador constituye una característica inherente y definidora del poseedor y establece con éste una relación de integridad semántica o complementariedad referencial, o de otra manera: el poseedor es tal gracias a tener esa propiedad o cualidad. La construcción surge, en nuestra opinión, cuando, desde la perspectiva del hablante o narrador-escritor, es crucial señalar el vínculo poseedor-poseído como inherente o complementario, de ahí que aparezca en pasajes textuales especiales o discursivamente relevantes, de ahí su baja frecuencia frente a otras expresiones posesivas, de ahí su elevada especialización referencial en cuanto a accesibilidad y persistencia, y de ahí la caracterización que se puede hacer como una construcción pragmáticamente controlada, y no tanto sintácticamente, en cuanto que el sintagma artículo + posesivo surge a partir de la elaboración textual que el escritor o narrador realice. Es una construcción marcada porque, como veremos enseguida, hace explícito el vínculo de integridad semántica entre poseído y poseedor y es, por lo tanto, más específica en significado que otras estructuras posesivas, que pueden o no hacer explícito el vínculo, dado el carácter no marcado de estas últimas. Es frecuente, en perspectiva tipológica, que las lenguas tengan expresiones posesivas especiales para significados pose-

${ }^{46} \mathrm{Cf}$. los artículos ya mencionados de Meier, «'Meu pai - o meu pai’. O artigo antes de adj. possessivo + nome de parentesco na linguagem falada», y de Lapesa, «Sobre el artículo ante posesivo en castellano antiguo». 
sivos especiales ${ }^{47}$. En cuanto a esta variable, todo el corpus muestra consistencia, y lo mismo en perspectiva diacrónica a lo largo de todo el español medie$\mathrm{val}^{48}$. A mi modo de ver, el «carácter gramaticalmente huidizo y estilístico» de la construcción señalado por los estudios tradicionales sobre el tema (véase supra $§ 2$ ) se comprende cuando se analiza el vínculo de integridad semántica entre poseedor y poseído.

Los ejemplos (10), (11) y (12) muestran este vínculo. Son algo extensos porque sólo en el contexto se puede entender este significado de integridad semántica (indico con ... el corte de alguna línea para abreviar, pero en los ejemplos las construcciones artículo + posesivo forman parte del mismo fragmento; se marcan en cursivas las apariciones léxicas del poseedor). El ejemplo (10) pertenece al capítulo II del libro Levítico de la General estoria. Primera parte, y en él se exponen las razones por las cuales Dios, a pesar de que los judíos lo traicionarían, mantuvo la antigua ley hebraica, ya que es ella la base de los principios y fundamentos de la iglesia cristiana, creada una vez que Dios padre toma forma en Dios hijo y éste realiza el sacrificio de su muerte para redención de los hombres. Puede verse que aparecen con doble especificador, como construcciones, todos los nominales que son definitorios de Dios-Cristo y constituyen sus caracterizadores intrínsecos: los sos santos padres, la su gloria, la su encarnación, la su passión, la su ley, el su resucitamiento, la su eglesia, y ellos son, sin duda, la razón de ser de la existencia de la cristiandad ya que gracias a esos caracterizadores Dios redime a la humanidad ${ }^{49}$. Es decir los nominales poseídos establecen una complementariedad referencial e integridad semántica con el poseedor Dios-Cristo. Se aprecian en el ejemplo las propiedades semántico-pragmáticas que hemos identificado como características de la construcción: una intensa persistencia referencial del poseedor, dada su alta accesibilidad - Dios es un tópico global, posiblemente el tópico global por excelencia en la cosmovisión medieval—, así como la persistencia de varios de los poseídos y el efecto de activación de la construcción, ya que se concentran en un mismo pasaje y algunas repiten incluso léxicamente el mismo poseído.

${ }^{47}$ Cf., Tobin, Invariance, markedness and distinctive feature analysis, ya citado, capítulo 4, y Bernd Heine, Possession. Cognitive sources, forces, and grammaticalization, Cambridge, Cambridge University Press, 1997, en particular el capítulo 2.

${ }^{48} \mathrm{Cf}$. mis trabajos en prensa, mencionados anteriormente, «Artículo + posesivo + sustantivo y estructuras afines» y «Gramaticalización y frecuencia de uso. Los paradójicos sintagmas con artículo + posesivo en el español medieval».

${ }^{49}$ Merece la pena hacer notar que en el capítulo subsecuente del Levítico en la General estoria, Primara parte, el capítulo IV, en que se describe la ley previa a la otorgada por Dios, calificada en el texto como falsa, no aparece ni una sola construcción con artículo + posesivo; es decir, la falsa ley no amerita establecer un vínculo de integridad semántica. 
(10) A Dios non se asconde ninguna cosa, onde sabié él cómo errarién los judíos contra él e non se guardarién ende, ca omnes eran. Mas peró por todo esso non los quiso él desamparar, e fízolo por amor de los sos santos padres Abraham, Isaac e Jacob... E quiso él averles merced... de guisa que cuando él tomasse carne en forma de omne e moriesse en la cruz segund la carne por el linage de los omnes... e resucitasse al tercer día, que passasse consigo la su gloria a los que lo oviessen merecido... Ca es de saber que ante que él naciese de santa María e tomasse muerte segund la carne que d'ella tomó por salvar el linage de los omnes... cuando viniéremos a fablar de los fechos del tiempo de la su encarnación e passión e resurrectionem,... assí como cuentan las escrituras de los santos padres e de la fe de Cristo e de la su eglesia... E esto non fue assí después de la su passión, ca los que en él crovieron después d'ella e andudieron segund los mandados de la su ley e sin pecado mortal morieron non fueron a infierno... E Nuestro Señor Dios por fazer esta merced a los judíos que buenos oviessen seído de sacarlos de pena en el su resucitamiento e passar a la su eglesia enseñóles fazer sacrificios e dar primicias e diezmos, e dioles leyes (GEI, 2.425)

El ejemplo (11), perteneciente a Castigos, concentra los atributos del rey a través de construcciones artículo + posesivo que introducen poseídos concretos pero que están empleados metafóricamente como símbolos del poder, ya que operan como caracterizadores de la autoridad real. El rey es tal y manifiesta su poder gracias a tener la su palabra, poseer la su espada con la que combatir a los sus enemigos y hacer justicia, usar la su pénnola para firmar y escribir órdenes en las sus cartas; a manera de pantócrator, el rey sostiene en la su mano derecha y la su mano siniestra propiedades y cualidades reales diversas. Obsérvese que sólo aparecen los atributos del poder introducidos mediante artículo + posesivo al ser mencionados por primera vez, ya que ahí es crucial hacer explícito el vínculo que hemos llamado de integridad semántica, y una vez presentados, se actualizan con una forma no marcada, ya sea artículo, ya posesivo simple. Vuelve a apreciarse la alta accesibilidad del poseedor, la fuerte persistencia de las dos entidades involucradas en el vínculo posesivo y el efecto de activación o priming, a través, por ejemplo, de las varias repeticiones del sustantivo manos con doble especificador.

(11) En la su mano derecha tiene aquel rey vna espada, por la qual se demuestra la justiçia en que deue mantener su regno, que así commo la espada taja de amas partes, así la justiçia deue tajar egual mente... Ca el poder del rey todo es en tres cosas. Lo primero en la su palabra. Lo segundo en la su pénnola con que escriue las sus cartas de lo que ha de mandar. La terçera en la su espada con que apremia a los sus enemigos e con que faze justiçia en los suyos. Ca la espada taja por premia e por justiçia las cabeças... E la pénnola sinon escriue como deue el rey déuele cortar a ella la cabeça... E sobre todo es mayor la palabra del rey... En la su mano siniestra teníe vna mançana redonda toda de oro 
e ençima de la mançana vna cruz de oro... En la su mano derecha tiene este rey una lua labrada con oro e muy rica... En la su mano siniestra tiene otra lua otrosí muy rica e muy buena, la qual era llamada amparança, ca sabida cosa es... (Castigos, 11.145)

El ejemplo (12) expone la correlación posesiva Caín el su pecado. El capítulo VIII de la Estoria alfonsí presenta a Caín y Abel, su linaje y la muerte del último a manos del primero; tras varias menciones del primero se introduce, en el capítulo IX, la FN doblemente especificada el su pecado, repetida varias veces en el tramo textual siguiente, donde Caín sigue apareciendo referido, pero ya como pecador, maldito por Dios. Es decir, la frase con doble clítico aparece cuando la narración muestra a Caín como pecador y no antes, y, en efecto, lo que define a este personaje bíblico es el pecado de la envidia. Esto es, el rasgo caracterizador esencial a Caín es ser pecador, de ahí la múltiple mención del nominal pecado con artículo + posesivo. En ese mismo fragmento aparecen también las FN sobreespecificadas la su sangre y la mi nemiga; la primera FN constituye la prueba del pecado - apoyan esta interpretación los verbos testigualo y esparzist-, la segunda, la mi nemiga, es la confirmación y consecuencia del atributo de ser pecador.

Andados cient e quinze años... de cuando Adam fuera fecho, mató Caím a Abel e pesó mucho a Dios con este fecho que fiziera tan malo Caím en Abel. E dixol Nuestro Señor Dios: -Caím, ¿dó es Abel tu hermano, ca muchos dias á quel non vi contigo nin andar aqui? Caím quando esto oyo ovo miedo que sabido era el su pecado e respusol que non sabié d'él, e que much avié quel non viera. Demandól essora Dios afincadamente... Caím fue sañudo por ello e repondiól bravamientre... Maltraxo estonces Dios a Caím e dixol: -Cata qué feciste, ca la boz de la sangre de tu hermano llama a mí dela tierra e se me querella. E ¿cómo me niegas tú agora la verdat?, ca túl mateste, e queréllalo e testígualo la su sangre que tú esparzist sobre la tierra, onde seras tú por ende maldito... Caím quando esto oyó dixo a Dios: - Bien veyo que mayor es la mi nemiga e el mi pecado que el perdón que yo ende merescría e avría meester de aver (GEI, 1.16-17)

En (13) aparecen listadas varias de las correlaciones poseedor-poseído con posesivo de $3^{\mathrm{a}}$ persona documentadas en el corpus. Las de $1^{\mathrm{a}}$ y $2^{\mathrm{a}}$ persona confirman el vínculo semántico. Para no cargar tipográficamente el texto, sólo se indica el poseedor y el poseído en una de las documentaciones, aun cuando varias de estas correlaciones se repiten dentro del texto en cuestión, o incluso la misma correlación aparece a lo largo de varios textos. Con posesivos de $1^{\mathrm{a}} \mathrm{y}$ $2^{a}$ persona es mucho más evidente el carácter inherente del vínculo. Se produce con estos sintagmas un efecto de complementariedad o equivalencia referencial entre poseedor y poseído, ya que este repite en buena medida las características o atributos referenciales conocidos del poseedor: al enemigo o al 
contrario: la su maldad; al moro: la su falsedat de creencia; a Dios: los sus santos, la su merced o la su misericordia; al sol: la su claridad; al hombre de Dios: la su oración; al mar: las sus aguas; a la ciencia: los sus significados; a Abraham: el su sacrificio; al rey: el su consejo, los sus vasallos; a los judios: la su salida-éxodo, etc. Esto es, no se puede entender lo que es un rey sin sus vasallos, sin un consejo, sin firmeza o esfuerzo; lo que define a Dios es tener una corte celestial, poder y ser misericordioso; lo definitorio del sol es su claridat, del mar, su agua, del enemigo, la maldad, de los judíos, el éxodo, etcétera. En todas las correlaciones se hace transparente que el vínculo de integridad semántica y complementariedad referencial que establecen poseedor y poseído es una constante y una propiedad definidora de la construcción.

(13) Dios / el Criador... con todos los sos santos (Cid, 1750)

Myo Çid... la su barba velida (Cid, 274)

Mio Çid... los sos vassalos (Cid, 1712)

de los falsos... las sus falsedades (Calila, 178)

el rey... la su grant merçed (Calila, 197)

el ome bueno... el su saber (Calila, 93)

Venus... los sus amores (GEII, 1.204.9b)

El sol... la su claridat (GEII, 1.91.33b)

los mensageros... la su venida (GEII, 1.204.9b)

Abraham... el so sacrificio (GEII, 1.45.32a)

el sabio... la su sapiencia (GEII, 1.69.20a)

los iudios... la su sallida (GEII, 1.18.15b)

el mar... las sus aguas (GEII, 1.104.12b)

Ercules... el su arco et la su porra (GEII, 2.17.5b)

los signos... las sus significationes (Cruces, 159.51b)

el sol... la su lumbre e los sus rayos (GEI, 1.224)

el Nilo... las sus aguas $(G E I, 1.226)$

los pastores... los sos ganados (GEI, 1.23)

Moisén... la su morada del desierto (GEI, 1.23)

el rey... el su heredero (Castigos, 15.165)

el rey... del su regno (Castigos, 11.150)

todas las otras madres... los sus fijos (Castigos, 5.100)

omne mesquino... las sus obras malas (Castigos, 3.90)

Dios... el su poder (Setenario, 108.3)

Dos rasgos gramaticales apoyan esta interpretación de las construcciones artículo + posesivo. 1) Por una parte, como se aprecia en varios de los ejemplos de arriba, con mucha frecuencia el poseído repite léxicamente la raíz morfológica del poseedor: rey el su reinado, rey el su regno, señores el su señorío, sabio la su sapiencia, signos las sus significaciones, falsos las sus falsedades, etc., lo cual, icónicamente, confirma el carácter inherente del poseído para el poseedor, esto es, la integridad semántica entre ambos, ya que repite no sólo el significado, sino también buena parte del significante del poseedor, es decir, un 
efecto de complementariedad doble: referencial y formal, contribuyendo con tal repetición a intensificar el vínculo entre poseedor y poseído. 2) Por otra parte, el poseedor y la construcción poseída aparecen con mucha frecuencia coordinados mediante la conjunción copulativa $e(t) / y$, como se ejemplifica en (14a), o bien, con menor frecuencia, el poseído opera como un adnominal o un complemento comitativo del poseedor, como en (14b), todo lo cual puede interpretarse como que poseedor y poseído constituyen una sola unidad conceptual y establecen un vínculo que se presenta como indisoluble en el discurso narrado.

(14) a. que por esta razon de los ydolos $e$ de las sus suziedades... les tollio ell esta tierra tan buena (GEII, 1.108.27a)

Grado a Dios et a las sus vertudes santas (Cid, 924) así asmaron muchos de la fuente del Nilo $\boldsymbol{e}$ del su nacer $(G E I, 1.228)$

b. Myo Çid con los sos vassallos pensso de caualgar $(\mathrm{Cid}, 376)^{50}$

La coordinación copulativa del poseedor con el poseído, la repetición del radical del poseedor en el poseído y la equivalencia o complementariedad referencial entre poseedor y poseído son recursos gramaticales que, juntos o por separado, forman una constante en la configuración de la construcción artículo + posesivo en los textos medievales analizados. Cabe para estos sintagmas, por tanto, una caracterización en términos retóricos, ya que parecen constituir la figura conocida en la retórica clásica como sinonimia, definida por Lausberg ${ }^{51}$ como: «intensidad semántica, que presupone diferencias semánticas en los sinónimos... Algunas sinonimias están habitualizadas fraseológicamente... Diversidad de significación por énfasis», con un efecto de «acumulación», para emplear el término de Lausberg (págs. 145-146), en los casos que en el corpus presentan repetición léxica-morfológica y coordinación.

La relación de integridad o complementariedad semántica que se aprecia en los ejemplos de (10)-(13) es posible, en buena medida, a mi modo de ver, gracias al hecho de que estas construcciones mantienen o arrastran el significado reflexivo originario del posesivo latino ${ }^{52}$; el poseído en estas construcciones se puede interpretar como 'propio o característico de', sin duda un reflejo de la

${ }^{50}$ Este verso admite dos lecturas estructurales: como complemento adnominal de myo Cid, que es la lectura que me parece más probable, y como un complemento circunstancial comitativo dependiente del verbo cavalgar. Parto para la primera interpretación del orden adyacente de los dos sintagmas, del hecho de que el núcleo verbal es una perífrasis con un verbo de entendimiento como rector, penssó, y el verbo de acción, cavalgar, está subordinado a aquel, y, desde luego, de que la interpretación como unidad se aviene bien con la hipótesis de integridad semántica entre poseído y poseedor.

${ }^{51}$ Heinrich Lausberg, Elementos de retórica literaria. Introducción al estudio de la filología clásica, románica, inglesa y alemana, Madrid, Gredos, [1963]1993, en particular las págs. 139-141.

52 Alfred Ernout y François Thomas, Syntaxe latine, Paris, Klincksieck, [1951] 1953, págs. $179-182$. 
correferencia reflexiva etimológica del posesivo en latín ${ }^{53}$. Este rasgo de reflexividad que se percibe en muchas de los sintagmas doblemente especificados no es sino la propiedad de persistencia, señalada por Hopper ${ }^{54}$ como característica de los procesos de gramaticalización, o en otras palabras, que las formas arrastran su significado etimológico por siglos y es precisamente ese significado el que hace posible que la forma en cuestión entre a nuevos contextos, aquéllos que le son sintáctica y semánticamente muy afines ${ }^{55}$. En (15) pueden verse algunos ejemplos que mantienen de manera clara este matiz reflexivo del posesivo: su propia persona y el estado que es propio de un rey en (15a), mi propio amigo en (15b), y en este caso la función como vocativo afianza la lectura reflexiva, o bien en (15c) el adjetivo propio confirma la reflexividad, por contraposición al nombre común genérico, comunales, citado inmediatamente antes.

a. Non cae al rey abiltar la su persona e despreçiar el su estado e por sabor que aya de fazer bien e onrar a otro (Castigos, 11.148)

b. $\quad$ Et llamólo el gato, et díxole: — ¿Por qué non te llegas a mí, el mi amigo que tan grant merçed me feziste (Calila, 271)

c. peró cadaúno d'aquellos faraones avié sin estos nombres que eran comunales de tod ell alcavera el su nombre proprio, e assí fazié este Faraón, e diziénle Amosis, como es dicho (GEI, 1.409)

El carácter semántico marcado y tan especializado que acabamos de ver a lo largo de estos tres apartados contribuye a producir un efecto formulaico de la construcción artículo + posesivo, ya que se repiten los mismos lexemas poseídos, al interior de un texto e incluso entre textos, y se repiten asimismo los poseedores, ya que, como cabe esperar, no hay tantas entidades capaces de constituirse en tópicos primarios y sostenerse a lo largo de uno o varios fragmentos narrativos. La repetición de los mismos lexemas poseídos, además de la repetición del radical del poseedor en el poseído aportan, sin duda, una con-

${ }^{53}$ De hecho, puede decirse que la construcción es más posesiva que presentativa, ya que cuando se puede trabajar con ediciones críticas que contienen aparato de variantes y se puede hacer la confrontación entre los diversos testimonios, se observa que los copistas omitían el artículo de estos sintagmas con mucha mayor frecuencia que el posesivo, aproximadamente en una relación de dos o tres omisiones de artículo por una de posesivo; cf. Company «Artículo + posesivo + sustantivo y estructuras afines», ya referido, en prensa.

54 Paul J. Hopper, «On some principles on grammaticization», en Approaches to grammaticalization, volumen 1, E. C. Traugott y B. Heine (eds.), Amsterdam, John Benjamins, 1991, págs. 17-36.

55 Si la forma o construcción entra en un verdadero proceso de gramaticalización, empezará a aparecer en contextos cada vez más alejados de su valor etimológico, señal de que se está generalizando en la lengua y, por tanto, gramaticalizando, cosa que creo no ocurrió con estas construcciones medievales, motivo por el cual no se gramaticalizaron plenamente y motivo por el cual también, entre otras razones, se perdieron del sistema. Para esta gramaticalización truncada, cf. mi trabajo en prensa, ya referido, «Gramaticalización y frecuencia de uso. Los paradójicos sintagmas con artículo + posesivo en el español medieval». 
figuración de estos sintagmas como un tanto redundantes o superfluos en una primera lectura. Se ha dicho que la repetición en la lengua lleva a una ritualización y a una habituación, mismas que hacen posible que la estructura en cuestión sea más fácil de reconocer y de reproducir ${ }^{56}$; merece la pena volver a destacar la expresión «habitualizadas fraseológicamente» que emplea Lausberg para caracterizar la sinonimia retórica. Como ya dije, la construcción artículo + posesivo opera como una fórmula estructural, sin llenado léxico previo pero bastante predecible o predeterminado, pronta a ser usada cuando en un fragmento discursivo específico se desea caracterizar una relación posesiva como esencial o inherente, al punto de que amerita una doble marca presentadora. El hecho de que en el español no se generalizaran estos sintagmas - a diferencia, por ejemplo, de lo que ocurrió en gallego-portugués y en buena parte en el catalán- puede explicar por qué nunca perdieron este carácter marcado; o viceversa, su carácter tan marcado impidió su plena gramaticalización y generalización.

Otras FN en español, introducidas bien por artículo simple y complemento adnominal en función de poseedor, la casa de Juan, bien por posesivo simple, su casa, pueden establecer un vínculo poseedor-poseído. Frente a estas dos construcciones, las de doble clítico son formalmente muy marcadas, ya que llevan una doble marca, de actualización y de posesión, y son semánticamente también muy marcadas, puesto que, como acabamos de ver, aportan un contenido informativo muy especializado. De hecho, con los tres sintagmas posesivos se puede establecer un continuum o escala de marcación. Veamos.

1) El menos marcado es el encabezado por artículo simple, ya que puede no sólo significar posesión estricta, como en la casa de Juan, sino también otro tipo de relaciones más o menos alejadas del valor de posesión, como, entre otras, continente-contenido: el agua de la laguna, parte-todo: el tejado de la casa, actividad de un individuo: el baile de María, etc., e incluso no posesivas, como el complemento de materia: la casa de madera, además de que el artículo admite lecturas genéricas que no son posibles ni con posesivo simple ni con artículo + posesivo (cf. supra $\S 3$ ).

2) Le sigue en la escala de marcación el sintagma encabezado por posesivo, ya que sólo admite lecturas posesivas y definidas, pero es flexible en cuanto al tipo de poseídos que pueden ser núcleo de la FN y es flexible también en cuanto al tipo de poseedores, ya que estos no son necesariamente tópico primario ni deben sostenerse en la línea narrativa principal.

3) Finalmente, el sintagma más marcado es el encabezado por los dos clí-

${ }^{56}$ Cf. John Haiman, «Ritualization and the development of language», en Perspectives on grammaticalization, W. Pagliuca (ed.), Amsterdam, John Benjamins, 1994, págs. 3-28, especialmente pág. 6 . 
ticos, ya que sólo admite lecturas posesivas y definidas con anclaje pragmático, nunca lecturas genéricas, pero además está especializado tanto para introducir un cierto tipo de poseídos como para vincularlos sólo a un cierto tipo de poseedores con los cuales entabla una relación de integridad semántica y complementariedad referencial, y para mantener en el decurso narrativo las dos partes integrantes de la relación posesiva ${ }^{57}$.

Correlato directo de la distinta ubicación de estos tres sintagmas en la escala de marcación es su diferente frecuencia de uso y sus diferentes capacidades distribucionales: el menos marcado, el introducido por el artículo, es el más frecuente (véase nota 4) y prácticamente no ofrece restricciones de complementación y distribución, le sigue en frecuencia el encabezado por posesivo simple, y el menos frecuente con mucho y con fuertes restricciones de distribución es el más marcado, el de doble clítico. Otros sintagmas posesivos del español, la casa suya, su casa de Juan, del Cid entró su carta, etc., podrían ser ubicados en esta escala de marcación de posesión, pero su análisis excede el objetivo de este trabajo. Por lo tanto, cuando diferentes expresiones se ubican en una escala de marcación, las expresiones menos marcadas pueden, desde luego, cubrir el significado y distribución de la más marcada, aunque sin el efecto comunicativo especializado que aporta esta última. Ello permite explicar, a nuestro modo de ver, por qué con relativa frecuencia en un mismo fragmento pueden alternar las distintas estructuras posesivas, incluso con un mismo sustantivo, introducidas por posesivo o por artículo o por ambos clíticos.

\section{LA FORMA AL SERVICIO DEL SIGNIFICADO: LA ESTRUCTURA INTERNA DE LA FN CON ARTÍCULO + POSESIVO}

La solidaridad de las dos caras del signo lingüístico es un hecho bien conocido del análisis lingüístico desde Saussure, particularmente explotada en los marcos funcionalistas del cambio lingüístico en la línea de procesos de gramaticalización. En efecto, cabe esperar que a una construcción semántica y pragmáticamente especializada corresponda una configuración formal también marcada.

${ }^{57}$ La alta especialización pragmático-discursiva de esta construcción plantea el problema de si alguna vez tuvo verdadera productividad en la lengua oral cotidiana del medioevo. Plantea, pues, el clásico e importante problema de la filología de cuál es la relación entre la lengua hablada y la escrita. Posiblemente, artículo + posesivo fuera una estructura propia de la lengua escrita, quizá también de la lengua oral muy culta y cuidada, y en la lengua oral cotidiana nunca rebasara los contextos con poseídos de parentesco, cuya integridad semántica con el poseedor es natural, y algunas otras pocas entidades, quizá las mismas que siguen siendo empleadas en los dialectos del español actual que mantienen de manera residual la estructura. 
La característica sobresaliente en la forma interna de la construcción artículo + posesivo es su escasa capacidad de llevar otros modificadores distintos de artículo + posesivo y las fuertes restricciones para acumular modificación y expansión ${ }^{58}$. Por lo general, son FN provistas únicamente con los dos clíticos y el núcleo sustantivo, y podrían considerarse por ello sintagmas cuasi escuetos ${ }^{59}$, ya que no suelen llevar ningún otro modificador que adjetive, especifique o aporte información sobre el sustantivo y no aceptan por lo general expansión acumulada. Las FN doblemente especificadas son cuasi escuetas arriba del $75 \%$ en la mayor parte del corpus (677 de 898 construcciones). No hay diferencias entre las tres personas del posesivo en cuanto al tipo de expansión o modificación. Bajo (16) se ejemplifica la forma usual de estas FN.

(16) a. E uos, Pero Vermuez, la mi seña tomad (Cid, 689)

E que la nuestra chancellería, que non sea metida en arrendamiento (THE, 1295, 7.86)

b. Las tus mañas yo te las sabre contar (Cid, 3315)

Et si por auentura uos Domingo Helipe, tovierdes este maiuelo labrado al vuestro finamiento, que nos den... (DLE, 1290, 69.103.20)

c. En la su quinta al Çid caen .C. cauallos ( $\mathrm{Cid}, 805)$ que si la su carrera fuere haz a oriente, faz lo sallir... et si la su carrera fuere haz a occident, mandal sallir (Cruces, 145.3b-5b)

El hecho de que lo usual sea la FN con el puro núcleo precedida de artículo + posesivo es indicativo de tres aspectos: $a$ ) que es innecesario aportar rasgos $\mathrm{u}$ otros significados descriptivos del nominal poseído núcleo, como si semánticamente sólo se requiriera presentar la entidad poseída y relacionarla con su poseedor, hecho que debe ponerse en relación con el rasgo de alta accesibilidad ya analizado, $b$ ) que el sustantivo poseído es un referente bien conocido y fácilmente identificable en el hilo narrativo, por ello no necesita información adicional en la frase, y $c$ ) que la concurrencia de artículo + posesivo parece saturar estructuralmente el sintagma nominal en cuanto a su capacidad de ex-

${ }^{58}$ Entenderé por modificación, los modificadores y adjetivos que se sitúan en el margen izquierdo del núcleo sustantivo de una FN, y por expansión, los modificadores que se sitúan a la derecha del núcleo, tengan estructura de frase o de oración. La modificación muestra restricciones para la concurrencia de las distintas clases de modificadores, con frecuencia, operan en la zona izquierda relaciones de distribución complementaria o exclusión, la expansión es, por lo regular, acumulable, aunque con restricciones léxicas para ciertos complementos; sigo en esta distinción a Company, La frase sustantiva en el español medieval. Cuatro cambios sintácticos, México, Universidad Nacional Autónoma de México, 1991, capítulo 1.

${ }^{59}$ Sigo el término y concepto de sintagmas escuetos propuesto por Ignacio Bosque para referir a FN con el puro núcleo sustantivo. La construcción artículo + posesivo estaría próxima a esa caracterización formal interna, en cuanto que en buena medida se bloquean o se saturan la modificación y la expansión; cf. su artículo, «Por qué determinados sustantivos no son sustantivos determinados», en El sustantivo sin determinación. La ausencia de determinante en la lengua española, I. Bosque (ed.), Madrid, Visor Libros, 1996, págs. 13-119. 
pansión y/o modificación. No se observan cambios diacrónicos en cuanto a la estructura interna de estas $\mathrm{FN}^{60}$, y ello quiere decir que estos sintagmas doblemente especificados nacieron con esa configuración gramatical: poco flexibles en cuanto a modificación y expansión, y que tampoco se flexibilizaron formalmente en su diacronía. Sin lugar a dudas, tal falta de flexibilización debió de ser otra de las causas que impidió la generalización y plena gramaticalización de estas construcciones.

Un $25 \%$ de estos sintagmas sobreespecificados lleva una expansión, como se ejemplifica en (17). Son formalmente una adjetivación, pero en su gran mayoría, desde el punto de vista semántico, son adjetivos u oraciones relativas especificativas que no describen ni especifican, sino que resultan un tanto superfluos o redundantes ya que no añaden información sobre el referente sustantivo en cuanto que operan como epítetos obvios que confirman las cualidades ya sabidas o esperadas del referente. En efecto, lo que se espera de una esposa es que sea conplida, del vasallo que sea fiel, de la corona que se lleve en la cabeça, de las virtudes de Dios que sean santas, de la lengua del escritor o narrador que sea el castellano, del caballo que sea corredor, etc. Es decir, son expansiones para lograr un efecto semántico connotativo y no denotativo, como lo sería una adjetivación descriptiva. Si atendemos a la división tradicional de la semántica en semántica denotativa o extensiva y semántica intensiva o connotativa, resulta muy notorio a lo largo de todo el corpus que las frases nominales con artículo + posesivo se sitúan en un plano de semántica intensiva y no extensiva en cuanto a su expansión.

(17) Ya doña Ximena, la mi mugier tan complida, / Commo a la mi alma yo tanto uos queria (Cid, 279)

¿Venides, Martin Antolinez, el mio fiel vassalo! (Cid, 204)

Mío fijo, vy estar vn rey muy noble asentado sobre vna silla. E estaua ý guarnido en la manera que te yo agora diré. La su corona que teníe en la cabeça era toda de oro (Castigos, 11.142)

Grado a Dios et alas sus uertudes santas ( $\mathrm{Cid}, 924)$

El griego dize .a. por lo que nos dezimos sin en el nuestro lenguage castellano (GEII, 1.5.8a)

et que mates el tu elefante blanco que cavalgas et a los otros doss elefantes presçiados, et el tu buen cavallo corredor (Calila, 282)

Las FN introducidas por artículo simple o por posesivo simple pueden también aparecer de forma cuasi escueta, como se muestra en (18a), pero, a diferencia de las encabezadas por artículo + posesivo, son también flexibles para admitir expansiones adjetivas que describen y añaden información que permita identifi-

${ }^{60}$ Cf. C. Company, «Artículo + posesivo + sustantivo y estructuras afines», ya citado anteriormente, nota 9. 
car al sustantivo poseído núcleo, como se ejemplifica en (18b): cristianas y extrañas son adjetivos necesarios para identificar el referente de gentes, e igualmente bueno y entendido son necesarios para identificar a omne. Pueden, al igual que las de doble clítico, recibir adjetivaciones superfluas con epítetos, como se observa en (18c): el alba siempre es en la mañana, los enemigos siempre son malos. Por lo tanto, los sintagmas posesivos con clítico simple, ya sea artículo ya posesivo, son formalmente no marcados o indiferentes en cuanto a su capacidad de expansión, ya que pueden expandirse o no, y en cuanto a la calidad de ella, ya que pueden tomar tanto una expansión denotativa descriptiva, que aporte información sobre el núcleo, cuanto una intensiva connotativa, mientras que los sintagmas posesivos con doble especificación son formalmente marcados para aparecer como FN cuasi escuetas y son semánticamente marcados para tomar sólo cierto tipo de adjetivaciones. Por lo tanto, los primeros operan en los dos planos semánticos, connotativo y denotativo, estos últimos, en cambio, sólo en el plano connotativo. En esquema: artículo + posesivo = semántica connotativa , artículo simple $/$ posesivo simple = semántica denotativa y connotativa.

(18) a. por las quales formas los signos recyben sus nombres (Cruces, 68.36a) Pedir uos a poco por dejar so auer en saluo ( $\mathrm{Cid}, 133)$

b. Grande duelo auien las yentes christianas (Cid, 29)

De Castiella uos ydes para las yentes estranas ( $\mathrm{Cid}, 176)$

Et entonçe començó el ome bueno a culparse (Calila, 93)

Et dizen que el omne entendido non se le encubre... (Calila, 257)

c. Tras nocharon de noch, al alua de la man (Cid, 1100)

Esto me an buelto myos enemigos malos ( $\mathrm{Cid}, 9)$

Un número importante de las FN con artículo + posesivo que son formalmente no escuetas se aproxima a un nombre propio de referencia única, en cuanto que contienen una expansión o una modificación que constituye una identificación del núcleo pero que no añade especificaciones nuevas de contenido sobre él, como se ve en (19), por lo cual, en cierta manera, se asemejan funcionalmente al esquema básico con sólo artículo + posesivo + sustantivo. En los casos de modificación, la FN con doble especificación lleva únicamente un solo modificador además del artículo + posesivo; no se documentan en el corpus del siglo XIII ni en siglos subsecuentes FN con modificadores adjuntos acumulados del tipo *todo el su gran señorío, *los sus dos blancos caballos, *las sus otras dos casas o *las otras sus dos casas, que son perfectamente posibles cuando la FN está encabezada por solo uno de los dos clíticos, ya sea artículo, ya posesivo.

e venimos a ti en nombre del to sennor Dios (GEII, 1.47.13a)

El mi Sennor Ihesu Christo non anda vestido de pannos de oro... E yo non creo que veniese el mi Sennor Ihesu Christo sy non en aquella forma que tomó la muerte en la cruz (Castigos, 1.77) 
Si conjuntamos las FN con el puro núcleo sustantivo, esto es, las que hemos venido llamando cuasi escuetas, ejemplificadas en (16), con aquéllas que contienen una expansión o una modificación que hacen el efecto de aproximar el núcleo sustantivo a un nombre propio, del tipo la vuestra real majestad, el nuestro señor Dios, como las ejemplificadas en (19), y añadimos aquéllas que llevan una adjetivación connotativa o intensiva, del tipo el mio fiel vasallo, ejemplificadas en (17), resulta que una gran mayoría de las FN sobreespecificadas rechaza estructura interna informativa, es decir, difícilmente llevan modificación o expansión que aporte información descriptiva sobre el referente. Lo anterior confirma el planteamiento inicial de este apartado, a saber, que existe solidaridad entre las dos caras del signo lingüístico y que la marcación o especialización semántica está respaldada y va de la mano de la marcación y especialización formal.

\section{CONCLUSIONES}

Del análisis anterior pueden extraerse algunas conclusiones, unas internas a la construcción que ha sido objeto de estudio, otras de naturaleza teórica. Hemos definido los sintagmas con artículo + posesivo como una 'construcción' y hemos intentado mostrar que su configuración formal y comportamiento semántico-pragmático tan especializados son consecuencia del carácter de construcción que la secuencia sintagmática con doble clítico adquirió a través de un proceso de gramaticalización. Hemos analizado cualitativa y cuantitativamente tres variables: accesibilidad del poseedor, persistencia referencial y el vínculo de integridad semántica entre poseedor y poseído, y hemos planteado en un último apartado que la estructura interna formal de la construcción es paralela, en cuanto a su marcación y especialización, a esas tres variables. Hemos propuesto que la construcción está pragmática o textualmente determinada y no tanto sintácticamente.

Asimismo, como consecuencia del análisis, hemos realizado la propuesta de que las expresiones posesivas del español se pueden ubicar en un continuum de marcación con dos extremos, el menos marcado de los cuales son los sintagmas posesivos introducidos por articulo simple y el más marcado y especializado, los introducidos por artículo + posesivo. Hemos establecido también una paradoja que se constituye como una constante de la construcción: su alta accesibilidad referencial y su elevada persistencia referencial se realizan a través de un mecanismo referencial de mucho peso fonológico, la repetición léxica, que es una estrategia usualmente empleada para entidades que informativamente conllevan baja o débil accesibilidad; hemos conectado tal paradoja con el carácter topical de los poseedores y con la naturaleza marcada de la construcción. 
Nuestro análisis de estas construcciones tan características del español medieval es, sin duda, complementario de los estudios ya clásicos de la estructura en términos estilísticos más que gramaticales. Nuestra aportación fue mostrar en qué consiste ese realce expresivo y valor estilístico señalado en los estudios tradicionales sobre el tema y comprobar que no existe un divorcio entre gramática, explotación pragmática y estilística, sino que, muy al contrario, los tres niveles o perspectivas son complementarios y van de la mano: precisamente, las restricciones formales y semánticas de la construcción las hacen ideales para explotación estilística y para aparecer sólo en determinados lugares textuales. Volvamos a insistir en que, en última instancia, el estilo no es sino la explotación, consciente o inconsciente, de los recursos gramaticales disponibles en una lengua.

Del análisis de los datos pueden extraerse también algunas conclusiones teóricas de interés para la relación entre la forma, el significado y el contexto en los procesos de cambio lingüístico. En primer lugar, más allá de la indudable arbitrariedad del signo lingüístico, existe una relación solidaria entre su lado formal y su lado semántico, de manera que a construcciones formalmente marcadas y de distribución restringida cabe esperar una caracterización semántica y pragmática también muy marcada y especializada. En segundo lugar, que el valor de las formas o construcciones no está aislado de su uso real en contextos específicos y no puede ser asignado con independencia del contexto, de tal manera que un contexto amplio, más allá del nivel de oración, simple o compuesta, se vuelve un nivel de análisis imprescindible para una mejor comprensión de la forma y significado de las estructuras de una lengua. Finalmente, el análisis ha intentado responder a la pregunta fundamental de la variación y el cambio lingüístico, formulada al inicio del trabajo: ¿por qué elegir una forma entre varias otras posibles, referencialmente equivalentes?, y ha mostrado que la elección nunca es al azar, sino que está determinada tanto por el significado invariante o constante de las formas, que en gran medida es consecuencia o dependiente del significado etimológico originario, como por el contexto en que la forma aparece, cuanto, desde luego, por el propósito comunicativo de los hablantes en una situación social y cultural determinada. 